\title{
Development of Auditory Brainstem Responses (ABRs) in Tshr Mutant Mice Derived from Euthyroid and Hypothyroid Dams
}

\author{
Pamela M. Sprenkle, ${ }^{1,2,4}$ JoAnn McGee, ${ }^{1-3}$ John M. Bertoni, ${ }^{2,4}$ And Edward J. Walsh ${ }^{1-3}$ \\ ${ }^{1}$ Developmental Auditory Physiology Laboratory, Boys Town National Research Hospital, Omaha, NE 68131, USA \\ ${ }^{2}$ Department of Biomedical Sciences, Creighton University, Omaha, NE 68178, USA \\ ${ }^{3}$ Department of Otolaryngology, Creighton University, Omaha, NE 68178, USA \\ ${ }^{4}$ Department of Neurology, Creighton University, Omaha, NE 68178, USA
}

Received: 11 September 2000; Accepted: 11 April 2001; Online publication: 1 August 2001

\begin{abstract}
Developmental changes in auditory brainstem responses (ABRs) to clicks and tone bursts were studied in genetically hypothyroid $T s h r$ mutant mice that were homozygous for the hypothyroid trait $(h y t / h y t)$, as well as in euthyroid individuals that were heterozygous for the trait $(+/ h y t)$. The developmental role of maternal thyroid hormones was determined by comparing homozygotes that were offspring of euthyroid $\left(h_{y} / h_{y} t_{(\mathrm{e})}\right)$ or hypothyroid $\left(h_{y t} / h_{y} t_{(\mathrm{h})}\right)$ dams; all heterozygotes were born to euthyroid dams $\left(+/ h y t_{(\mathrm{e})}\right)$. Clear responses to high-level stimuli were recorded from heterozygotes on postnatal day 12 (P12) for most stimulus conditions, and thresholds, response amplitudes, interpeak intervals, and latencies developed normally, achieving nearly adult properties by P21. Most hyt/hyt $t_{(\mathrm{h})}$ animals were unresponsive to acoustic stimulation throughout the period of study. Grossly immature responses to high-level stimuli were observed in many hyt/hyt $(\mathrm{e})$ pups on $\mathrm{P} 15$; however, clear, low-amplitude responses were not routinely observed until P21. Thresholds improved with age in $+/ h y t_{(\mathrm{e})}$ and $h y t / h y t_{(\mathrm{e})}$ individuals, and latency-level curves were relatively steep in young animals and developed normally in $+/$ hyt $_{(\mathrm{e})}$ mice with the most significant changes occurring between P15 and P21. In general, hyt/hyt (e) mice exhibited prolonged latencies,
\end{abstract}

Correspondence to: Edward J. Walsh, Ph.D. - Boys Town National Research Hospital 555 North 30th Street • Omaha, NE 68131. Telephone: (402) 498-6701; fax: (402) 498-6351; email: walsh@boystown.org interpeak intervals, and central conduction times throughout the age range studied, and slopes of latency-level curves remained abnormally steep through P28. Response amplitudes were generally larger in heterozygotes than in $h y t / h y t_{(\mathrm{e})}$ mice, regardless of level. Replacement of thyroxin during the first 10 postnatal days in $h y t / h_{y} t_{(\mathrm{h})}$ pups had little to no effect on the development of auditory function, although more animals from this group were responsive at very high stimulation levels. We conclude that auditory function is impaired in hypothyroid Tshranimals throughout development and that impairment is profound when individuals are not exposed to maternal thyroid hormone, i.e., a clear thyroxin-dependent critical prenatal period exists in the $T s h r$ mutant mouse.

Keywords: hypothyroidism, hearing, development, thyroid hormone, thyroid stimulating hormone

\section{INTRODUCTION}

When thyroid hormones are congenitally deficient in altricious mammals, delays are observed in the onset and maturation of cochlear potentials (Uziel et al. 1980), auditory reflexes (Deol 1973; Comer and Norton 1982), and the auditory brainstem response (ABR) (Uziel et al. 1983a; Hébert et al. 1985b). Anatomical correlates include delays in the opening of the external ear canal (Uziel et al. 1980), clearance of middleear mesenchyme (Uziel et al. 1980), and the transformation of Kolliker's organ and sensory cell primordia 
into a mature organ of Corti (Deol 1973; Uziel et al. 1981, 1983a). Depending on the duration and severity of hypothyroidism, auditory deficits can persist into adulthood, as demonstrated by apparently permanent changes in the cochlear microphonic (Uziel et al. 1983a), the VIIIth nerve compound action potential (Uziel et al. 1983a), behavioral thresholds (Goldey et al. 1995a,b), and the ABR (Uziel et al. 1983a; Hébert et al. 1985a,b; Albee et al. 1989; Meza et al. 1991). Based on findings from other laboratories, cochlear pathology appears to be widespread, including malformation of the tectorial membrane presumably as a result of continued secretory activity by cells of the inner sulcus epithelium (Legrand et al. 1988; Rabié et al. 1988), irregularities in the microtubular framework of the tunnel of Corti (Gabrion et al. 1984), and surface, cytoplasmic, and synaptic abnormalities of sensory cells (Uziel et al. 1983a,b; Prieto et al. 1990).

In a companion article, we reported that auditory function in the genetically hypothyroid mouse, commonly known as the $T s h r^{\text {hyt }}$ mutant or hyt mouse, is abnormal in individuals who are homozygous for the hyt allele. Acoustic thresholds are elevated, response latencies are prolonged, and amplitudes are attenuated in affected animals relative to normal, euthyroid littermates (Sprenkle et al. 2001). The findings from that study corroborate and extend the observations of O'Malley and his colleagues (O'Malley et al. 1995; Li et al. 1999), who also reported cochlear abnormalities in $h y t / h y t$ animals.

Hypothyroidism in hyt/hyt mice arises from a point mutation in the gene that encodes the thyrotropin receptor, a condition that prevents the synthesis of normal levels of thyroid hormone (Beamer et al. 1981; Beamer and Cresswell 1982; Stein et al. 1989, 1994). A fortuitous outcome of this genetic condition is that two distinct models of hypothyroidism are available in a single murine strain. If hyt/ hyt pups are derived from euthyroid, + / hyt dams, fetuses are exposed to maternal thyroid hormones, and in the case of homozygous pups born to hypothyroid, hyt/hyt dams, pups experience hypothyroidism from conception. Euthyroidderived $h y t / h y t_{(\mathrm{e})}$ mice exhibit typical signs of congenital hypothyroidism, including decreased body size (Beamer et al. 1981; Adams et al. 1989), neurochemical and behavioral defects (Noguchi and Sugisaki 1984; Adams et al. 1989; Laffan et al. 1989; Stein et al. 1991; Anthony et al. 1993; Li and Chow 1994), as well as auditory abnormalities (O’Malley et al. 1995), whereas $+/ h y t_{(\mathrm{e})}$ littermates appear phenotypically normal.

The characteristics of hypothyroid-derived $h y t / h y t_{(\mathrm{h})}$ mice, on the other hand, remain largely unknown (Erf 1993) because of the difficulty of initiating and maintaining pregnancies in the hypothyroid state (Hendrich et al. 1976). The probable importance of maternal thyroid hormones to murine hearing development is suggested by at least one report showing that the severity of cochlear pathology is enhanced when hypothyroidism is initiated in $\mathrm{C} 57$ mice prior to the onset of fetal autonomous secretion (Deol 1973). The coupling of pre- and postnatal hypothyroidism in the $h y t / h y t_{(\mathrm{h})}$ mouse may, therefore, lead to more severe hearing deficits than those observed in hyt/ $h y t_{(\mathrm{e})}$ animals.

Although untested, hearing defects in hyt/hyt mice could arise from anatomical and/or biochemical defects present prior to the onset of hearing or, alternately, from degenerative processes that become functionally significant only after hearing has developed. The answer to this question will be almost certainly complex, since hearing impairment is associated with both congenital and adult onset disease (Post 1964; Meyerhoff 1979; Anniko and Rosenkvist 1982; BenTovim et al. 1985; Di Lorenzo et al. 1995). The aim of the current study was to track the development of auditory function using the ABR and to determine the extent to which pre- and postnatal thyroid hormone levels influence the development of function in the Tshr mutant mouse.

\section{MATERIALS AND METHODS}

\section{Study design}

ABRs were recorded from independent groups of male Tshr mutant mice at ages approximating the onset of hearing, i.e., the age that responses to intense airborne sounds are first observed (P12, where $\mathrm{P}$ represents postnatal day), the period of rapid development (P15 and P21), and the mature condition (P28).

Experimental animals were generated using two distinct mating paradigms. In the first, offspring from litters produced by hyt/hyt male and $+/$ hyt female matings are designated $+/ h y t_{(\mathrm{e})}$ and $h y t / h y t_{(\mathrm{e})}$, with the subscript reflecting the euthyroid state of their dams. Eight to 12 mice were evaluated in each group at each age and subjects were drawn from 23 litters. In the alternative mating paradigm, offspring were collected from litters produced by hyt/hyt male and hyt/hyt female pairs; offspring are designated $h y t / h y t_{(\mathrm{h})}$ to reflect the hypothyroid state of their dams. This group was further subdivided into those that received postnatal thyroxin replacement therapy (designated $\mathrm{T}_{4}-$ hyt) $\left.h y t_{(\mathrm{h})}\right)$ and those that received saline placebo (hyt/ $\left.h y t_{(\mathrm{h})}\right)$. Six to nine mice were evaluated in each of these groups at each age and subjects were drawn from 18 litters. Each animal was studied at a single age. Creighton University's Animal Care and Use Committee approved the protocols employed in the care and use of animals used for this study. 


\section{Animal husbandry}

Animals were bred and housed as described in Sprenkle et al. (2001). Prior to and between matings, the chow (Formulab Chow 5008, Purina Mills, Inc., Richmond, IN, USA) of hyt/hyt animals used for breeding was supplemented with thyroid hormone to enhance fertility. In females, chow supplementation was discontinued seven days prior to the pairing of prospective mates and did not resume until all pups from a specified litter were harvested. Litters were culled to six pups within 24 hours of birth. Both male and female offspring remained with the dam until the time of testing.

\section{$\mathrm{T}_{4}$ replacement}

Either thyroxin or saline was administered to $h_{y} t / h_{y} t_{(\mathrm{h})}$ pups, as in Sprenkle et al. (2001), on a daily basis from birth ( $\mathrm{P} 0)$ through postnatal day 10 , a stage that has been identified as a critical, thyroxin-dependent, developmental period in mice (Deol 1973). Serum thyroxin levels in the group designated $\mathrm{T}_{4}-h_{y} t / h t_{(\mathrm{h})}$ were restored to normal, age-matched values via subcutaneous injections of thyroxin on days $0-5(4 \mathrm{ng} / \mathrm{g})$, $6-8(5.8 \mathrm{ng} / \mathrm{g})$, and $9-10(9.1 \mathrm{ng} / \mathrm{g})$.

\section{Serum $\mathrm{T}_{4}$ determinations}

Serum $\mathrm{T}_{4}$ levels were assayed according to the procedure of Beamer et al. (1981), and the method used for this study is described in more detail in Sprenkle et al. (2001). Blood was collected from the tail vein on the day of ABR testing and radioimmunoassays were performed in duplicate. The assay detection limit was $0.01 \mu \mathrm{g} / \mathrm{dL}$.

\section{Behavioral and physical assessments}

Daily records were made to identify gross physical changes (e.g., body weights and ages associated with eye-opening and pinna-unfolding) and behavioral differences (circling tendency, righting reflex, and posture) among the groups. Behavioral evaluations, described in more detail in Sprenkle et al. (2001), were routinely executed on P21 and P28.

\section{ABR measurements}

ABRs were recorded from individual mice on P12, P15, P21, or P28 [a more detailed discussion of the method can be found in Sprenkle et al. (2001)]. Subjects were anesthetized using chloral hydrate $(480 \mathrm{mg} / \mathrm{kg} \mathrm{IP})$ and supplemented with boosters $(120 \mathrm{mg} / \mathrm{kg})$ as needed. Body temperature was monitored throughout recording sessions and maintained at approximately $37.5^{\circ} \mathrm{C}$ using a heating blanket.

Digitally synthesized tone bursts $(3 \mathrm{~ms}$ in duration with $1 \mathrm{~ms}$ rise/fall times) and clicks (60 $\mu$ s in duration) were alternated in polarity and delivered at a rate of $5 / \mathrm{s}$ in the free field via a high-impedance piezoelectric tweeter positioned $10 \mathrm{~cm}$ from the subject's vertex. Stimulus levels were calibrated with a 0.5 in. microphone (Brüel \& Kjær, Norcross, GA) and are reported in decibels sound pressure level (dB SPL: referenced to $20 \mu \mathrm{Pa}$ ). Maximum output levels for clicks and 20, $16,8,4$, and $2 \mathrm{kHz}$ stimuli were 122, 112, 114, 118, 133, and $112 \mathrm{~dB}$ SPL, respectively. Thresholds to clicks and tone bursts at these frequencies were obtained, and response level series were acquired using both clicks and tone bursts $(20$ and $8 \mathrm{kHz})$ incremented from below threshold to $90 \mathrm{~dB}$ SPL in 5-dB intervals.

ABRs were recorded using subdermal electrodes positioned at the vertex (noninverting active lead), mastoid region (inverting reference lead), and over the neck musculature (ground). Differentially recorded signals were amplified $[100,000 \times]$, bandpass filtered $(0.03$ and $10 \mathrm{kHz})$, and sampled every 50 $\mu$ s over a 20-ms epoch that included a baseline period occurring $5 \mathrm{~ms}$ prior to stimulus delivery. A total of 500 trials were averaged for each recording and each ABR was replicated.

\section{Data analysis}

Two-way analysis of variance (ANOVA) was used to evaluate differences in body weights, and one-way ANOVA was used to test for differences in birth weights, and ages of eye-opening and pinna-raising among the groups. Tukey tests were used for multiple comparisons.

ABR thresholds, wave latencies, and amplitudes were measured as in Sprenkle et al. (2001). Nonparametric statistics (Kruskal-Wallis test) were used to make intergroup comparisons and differences were considered significant at the $p<0.01$ level.

\section{RESULTS}

\section{Somatic and behavioral characteristics}

Serum $\mathrm{T}_{4}$ levels in placebo-treated hyt/hyt mice derived from hyt/hyt females $\left(h_{y t} / h_{y} t_{(\mathrm{h})}\right)$ were always $<1.0 \mu \mathrm{g} /$ $\mathrm{dL}$ on P12, and serum titers did not increase over the age range studied in this investigation (Fig. 1). In contrast, serum levels measured in progeny of hyt/hyt male $\times+/$ hyt female matings fell into two distinct categories that were evident as early as P12 (Fig. 1, circles). With the exception of one borderline case, serum levels in one group were $<1.0 \mu \mathrm{g} / \mathrm{dL}$, as in the 


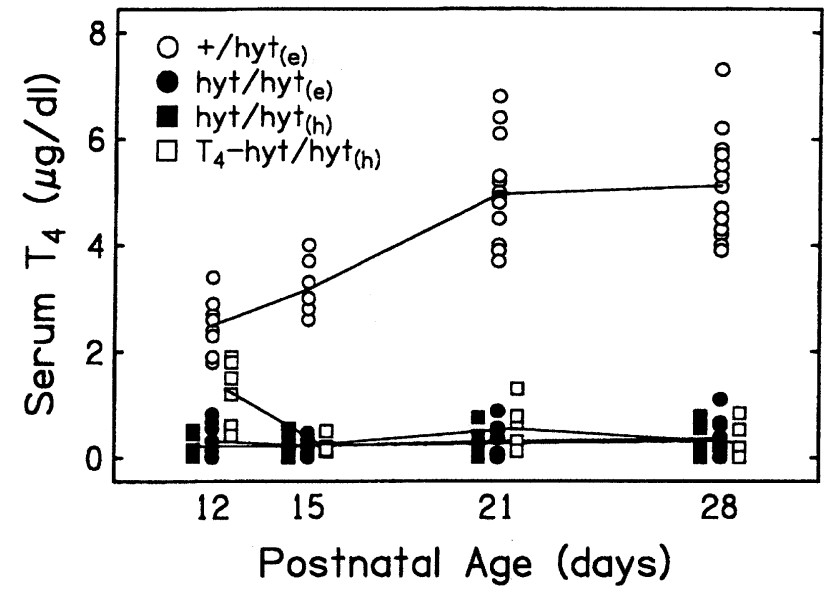

FIG. 1. Serum $\mathrm{T}_{4}$ levels in $T s h r$ mice. The relationship between serum $\mathrm{T}_{4}$ titers and age in individual hyt mice born to euthyroid (e) or hypothyroid (h) dams is shown. Lines represent averages for each experimental group.

$h y t / h y t_{(\mathrm{h})}$ group, and remained essentially constant for the course of the study. These individuals were assigned to the $h y t / h y t_{(\mathrm{e})}$ category. The serum level measured in the exceptional case was $1.10 \mu \mathrm{g} / \mathrm{dL}$ and the individual in question was placed in the $h y t / h y t_{(\mathrm{e})}$ category. $\mathrm{T}_{4}$ titers increased with age in heterozygotes, achieving adult values by P21. Differences between heterozygotes and homozygotes were evident in older animals, permitting the unambiguous assignment of offspring from heterozygous dams into $+/$ hyt and hyt/ hyt categories (Table 1 ). Among $h y t / h y t_{(\mathrm{h})}$ animals that were treated with thyroxin between birth and P10, serum $\mathrm{T}_{4}$ levels remained elevated relative to values measured in placebo-treated $\left(h y t / h y t_{(\mathrm{h})}\right)$ individuals on P12 $(p<0.01)$, although the mean titer was notably lower than in heterozygotes. By P15 serum levels had

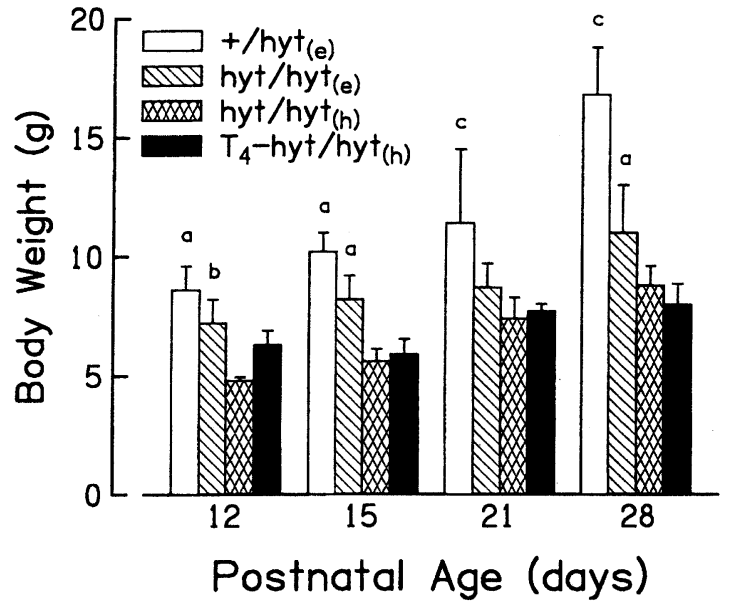

FIG. 2. Growth curves for euthyroid and hypothyroid mice. Mean body weights $( \pm S D)$ for each experimental group are plotted at the ages tested. Each group contained 6-13 mice at each age. Letter designations above bars represent statistically significant differences between the indicated group and the following groups: "a," vs. hyt/

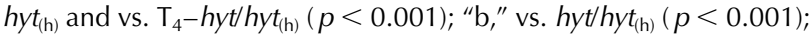
"C," vs. hythyt $t_{(\mathrm{h})}$ and vs. $\mathrm{T}_{4}-h_{y} t / h_{\mathrm{t}} \mathrm{t}_{(\mathrm{h})}(p<0.01)$. Significant differences were tested by two-way ANOVA.

fallen completely and were comparable to those observed in placebo-treated homozygotes.

Somatic deficits associated with maternal hypothyroidism were already apparent at birth. Progeny of hypothyroid dams had significantly smaller birth weights $(p<0.01)$ than offspring of euthyroid dams (Table 1). Body weight differences were striking by P28, the age that ABRs were tested (Fig. 2), and the mean weight of individuals in the $+/$ hyt $_{(\mathrm{e})}$ group was approximately twice that of the group derived from hypothyroid dams. Hyt/hyt $t_{(\mathrm{e})}$ mice were, on average,

\begin{tabular}{|c|c|c|c|c|}
\hline \multicolumn{5}{|c|}{ Somatic and behavioral characteristics } \\
\hline & $+/ h y t_{(\mathrm{e})}$ & hyt/hyt $t_{(\mathrm{e})}$ & hyt/hyt $t_{(\mathrm{h})}$ & $\mathrm{T}_{4}-$ hyt $_{\text {hy }} t_{(\mathrm{h})}$ \\
\hline \multicolumn{5}{|l|}{ Serum $\mathrm{T}_{4}^{1}(\mu \mathrm{g} / \mathrm{dL})$} \\
\hline P12 & $2.50 \pm 0.18,8^{a}$ & $0.32 \pm 0.12,8$ & $0.22 \pm 0.09,6$ & $1.30 \pm 0.26,6^{b}$ \\
\hline P15 & $3.17 \pm 0.20,7^{a}$ & $0.22 \pm 0.06,8$ & $0.22 \pm 0.06,9$ & $0.25 \pm 0.07,6$ \\
\hline $\mathrm{P} 21$ & $4.96 \pm 0.28,13$ & $0.31 \pm 0.11,8$ & $0.26 \pm 0.11,6$ & $0.55 \pm 0.19,6$ \\
\hline P28 & $5.12 \pm 0.27,13$ & $0.36 \pm 0.11,11$ & $0.31 \pm 0.12,6$ & $0.29 \pm 0.13,6$ \\
\hline Birth weight ${ }^{2}(\mathrm{~g})$ & $1.42 \pm 0.21,41$ & $1.45 \pm 0.20,85$ & $1.26 \pm 0.18,27^{c}$ & $1.26 \pm 0.04,24^{c}$ \\
\hline Eye-opening age ${ }^{3}$ & $14.8 \pm 1.6, \quad 26^{d}$ & $16.3 \pm 1.4, \quad 19$ & $16.8 \pm 0.9, \quad 12$ & $16.8 \pm 0.9, \quad 12$ \\
\hline Pinna-raising age ${ }^{3}$ & $15.6 \pm 1.2, \quad 26^{d}$ & $19.0 \pm 1.7, \quad 19$ & $19.4 \pm 1.1, \quad 10$ & $19.9 \pm 1.4, \quad 11$ \\
\hline Tail-hanging test & $0 / 26$ & $0 / 19$ & $0 / 12$ & $0 / 12$ \\
\hline Circling behavior & $0 / 26$ & $3 / 19$ & $1 / 12$ & $2 / 12$ \\
\hline
\end{tabular}

${ }^{1}$ Mean \pm SEM, number of animals tested.

${ }^{2}$ Mean $\pm S D$, number of animals tested.

${ }^{3}$ Mean \pm SD in postnatal days, number of animals tested.

${ }^{a} p<0.001$ vs. $+/ h y t_{(\mathrm{e})}$ at $\mathrm{P} 21$ and P28 using two-way ANOVA.

${ }^{\mathrm{b}} p<0.01$ vs. hyt/hyt $t_{(\mathrm{h})}$ at P12 using two-way ANOVA.

${ }^{c} p<0.01$ vs. + $/ h y t_{(\mathrm{e})}$ and $h y t / h y t_{(\mathrm{e})}$ using one-way ANOVA.

${ }^{\mathrm{d}} p<0.001$ vs. hyt/hyt $t_{(\mathrm{e})}$, vs. hyt/hyt $t_{(\mathrm{h})}$, and vs. $\mathrm{T}_{4}-$ hyt $_{\text {hyt }} \mathrm{t}_{\mathrm{h})}$ using one-way ANOVA. 
always heavier than $h y t / h t_{(\mathrm{h})}$ counterparts, but differences were not always significant.

Growth deficits in both groups of hyt/hyt mice were accompanied by delays $(p<0.001)$ in eye-opening and pinna-raising (Table 1), as shown previously for $h y t / h^{\prime} t_{(\mathrm{e})}$ mice (Adams et al. 1989; Sprenkle et al. 2001), and developmental delays were not dependent on exposure to prenatal thyroid hormone. Likewise, postnatal thyroid hormone exposure did not affect the timing of these events in $h y t / h_{y} t_{(\mathrm{h})}$ animals. Overt vestibular abnormalities were not apparent (Table 1) and circling was observed in a small percentage of each group, i.e., $16 \%(3 / 9)$ of $h y t / h y t_{(\mathrm{e})}$ mice and $8 \%$ $(1 / 12)$ of $h y t / h t_{(\mathrm{h})}$ mice tested on P21 and P28. Circling among $h y t / h_{y} t_{(\mathrm{h})}$ mice was not affected by exposure to postnatal thyroxin, i.e., $17 \%(2 / 12)$ of $\mathrm{T}_{4}-$ hyt/ $h_{\text {y }}(\mathrm{h})$ circled.

\section{Appearance of $\mathrm{ABR}$ waveforms}

Low-amplitude ABRs were observed in $+/ h_{\text {yyt }}(\mathrm{e})$ mice at the earliest age studied (Fig. 3B, top three tracings), with 90 -dB-SPL clicks eliciting responses in $25 \%$ of the heterozygotes studied and 90-dB-SPL tone bursts eliciting responses in nearly the entire sample of heterozygotes above $4 \mathrm{kHz}$. While the four peaks that characterize ABRs recorded from adults were observed in some 12 day olds, peak amplitudes and latencies were small and prolonged, respectively, in addition to being highly variable. By $\mathrm{P} 15$, all $+/ h_{y} t_{(\mathrm{e})}$ mice responded to intense stimuli (90-110 dB SPL), regardless of stimulus type, but amplitudes remained small and response latencies prolonged. Response characteristics changed dramatically between P15 and P21, as discussed in the following sections, such that completely mature waveforms were observed by the end of the third week. All four waves were observed in 12 of the $13+/$ hyt $_{(\mathrm{e})}$ 28-day-old mice studied. As in other mammals, response amplitudes increased and latencies decreased with age, and typical level-dependent characteristics were observed throughout development, as depicted for the $20-\mathrm{kHz}$ condition in Figure $4 \mathrm{~B}$. The overall appearance of the ABR on P21 and P28 was similar to that observed in 3-month-old heterozygotes in a companion study (Sprenkle et al. 2001).

Although not all individuals belonging to the hyt/ $h_{y} t_{(\mathrm{e})}$ category responded to clicks on P12, a large portion of the population $\operatorname{did}(\sim 75 \%)$, and waveforms recorded from responsive animals were grossly immature, typically consisting of two broad peaks identified as waves I and IV (Fig. 3A). Response characteristics were highly variable among $h y t / h_{y} t_{(\mathrm{e})}$ individuals when compared with responses recorded from $+/ h y t_{(\mathrm{e})}$ animals at all ages, and $h y t / h y t_{(\mathrm{e})}$ animals failed to achieve the same degree of maturity as individuals in the $+/ h_{y} t_{(\mathrm{e})}$ category, i.e., amplitudes remained small

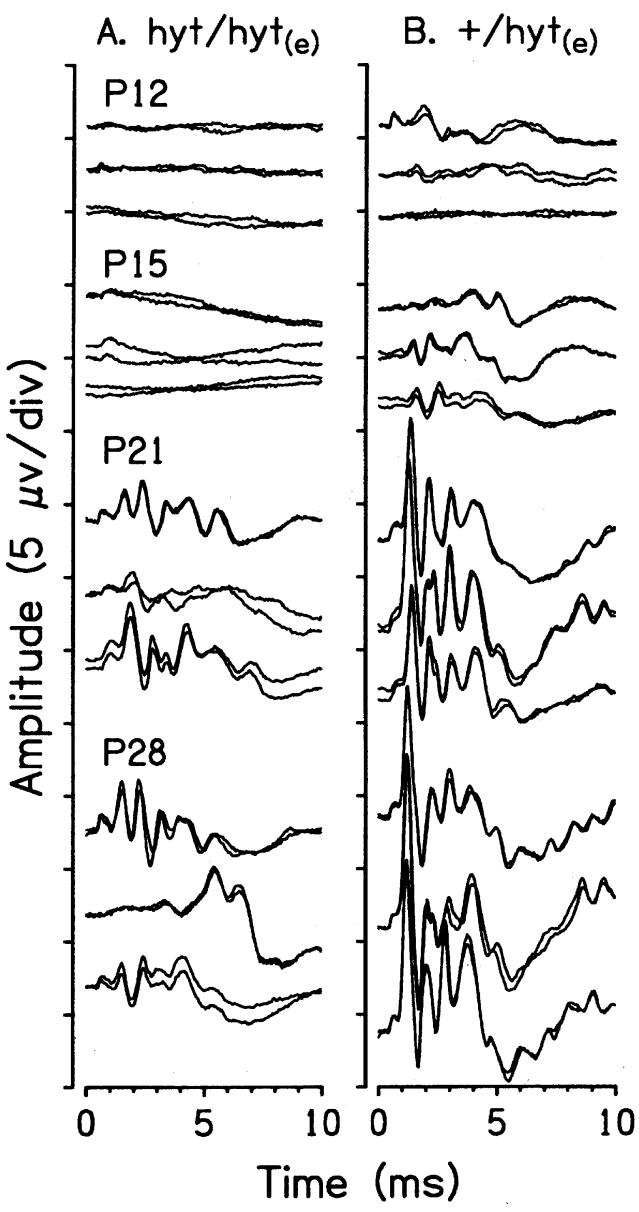

FIG. 3. Representative examples of ABR waveforms. Click-evoked waveforms were obtained from individual mice in two of the experimental groups (columns) and are plotted at the indicated ages (P12, P15, P21, and P28). Records of 3 individuals at each age are shown in response to $90 \mathrm{~dB}$ SPL stimuli. Two replicates are shown overlapping for each individual.

and latencies prolonged relative to heterozygous counterparts.

In striking contrast to the development of function in euthyroid-derived offspring, hypothyroid-derived homozygotes $\left(h y t / h_{(} t_{(\mathrm{h})}\right)$ failed to respond to $90-\mathrm{dB}$ SPL clicks at any age tested.

\section{Incidence of response}

The percentage of individuals from each group that responded to the maximum sound pressure available for specified stimulus conditions throughout the age range studied in this investigation is shown in Figure 5. Maximum output levels ranged between 112 and $122 \mathrm{~dB}$ SPL, except for the $4-\mathrm{kHz}$ condition where it was $133 \mathrm{~dB}$ SPL. Predictably, heterozygotes (open circles) were the most responsive of the groups studied here and, with few exceptions, all $+/$ hyt $_{(\mathrm{e})}$ individuals were responsive to clicks and tone bursts in each 


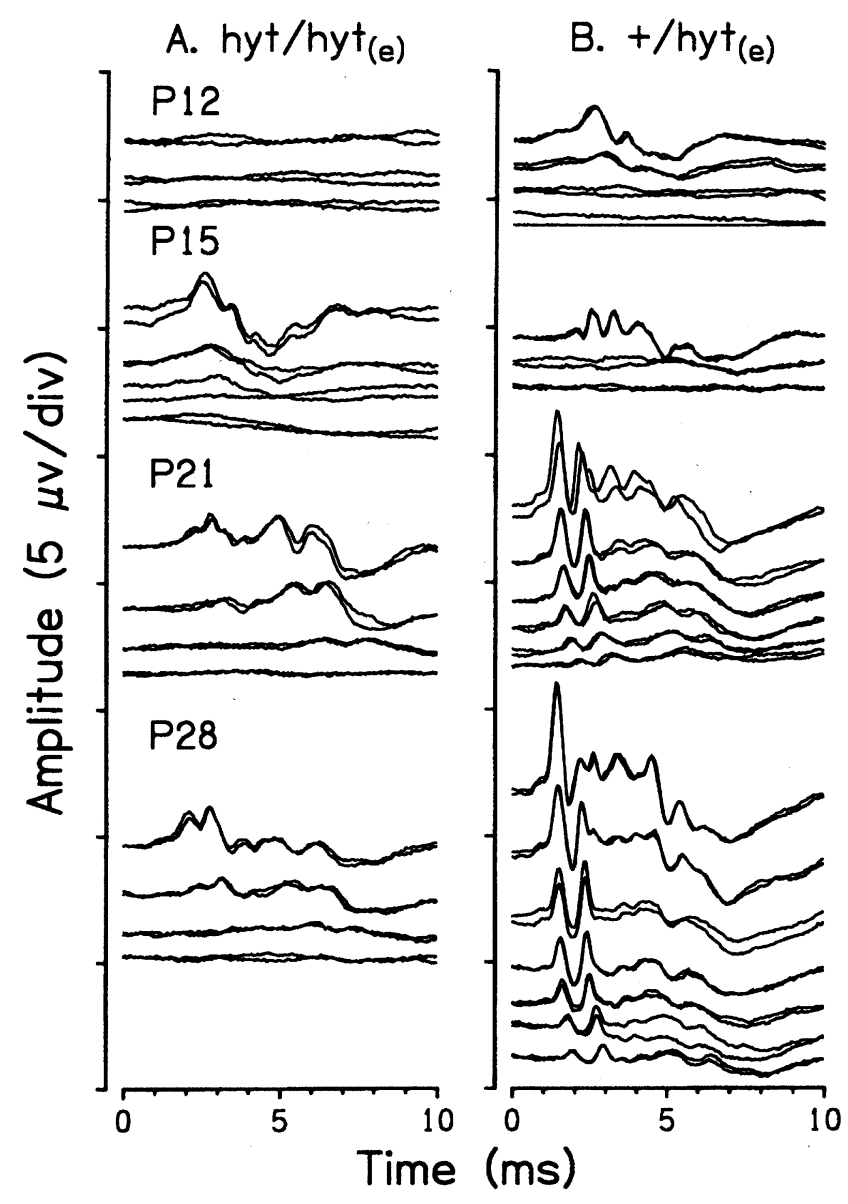

FIG. 4. Level-dependent changes in ABR waveforms. Representative examples of $A B R$ waveforms from homozygous mutants $(\mathbf{A})$ and heterozygotes $(\mathbf{B})$ derived from heterozygous dams are plotted at the indicated ages (P12, P15, P21, and P28) in response to a range of levels at $20 \mathrm{kHz}$. Two replicates are shown overlapping at each level. Each set of waveforms represents responses to stimuli starting at 90 $\mathrm{dB} S \mathrm{SP}$ (upper trace of set) and decreasing in 10-dB steps (successively lower traces).

recording session (Fig. 5). Interestingly, although homozygotes that were exposed to maternal $\mathrm{T}_{4}$, the $h y t / h t_{(\mathrm{e})}$ group (filled circles), were less sensitive as a group than their heterozygous cohorts on P12 and P15, all were responsive by P21, except in the case of $2 \mathrm{kHz}$. The decline of responsiveness at $2 \mathrm{kHz}$ in older pups may reflect the overall insensitivity and associated response variability of $T s h r$ mutants in that frequency range. Unlike homozygotes exposed to $\mathrm{T}_{4}$ prenatally, $h_{y t} /$ hyt $_{(\mathrm{h})}$ mice (filled squares) were grossly insensitive throughout development, and the curves representing this group were striking in their contrast with those representing other categories. Only rarely did the percentage of responsive animals from this group of homozygous individuals born to homozygous, hypothyroid dams rise above $30 \%$, except for $4 \mathrm{kHz}$, a finding that almost certainly reflects the higher output of the system at that frequency. Note that not a single

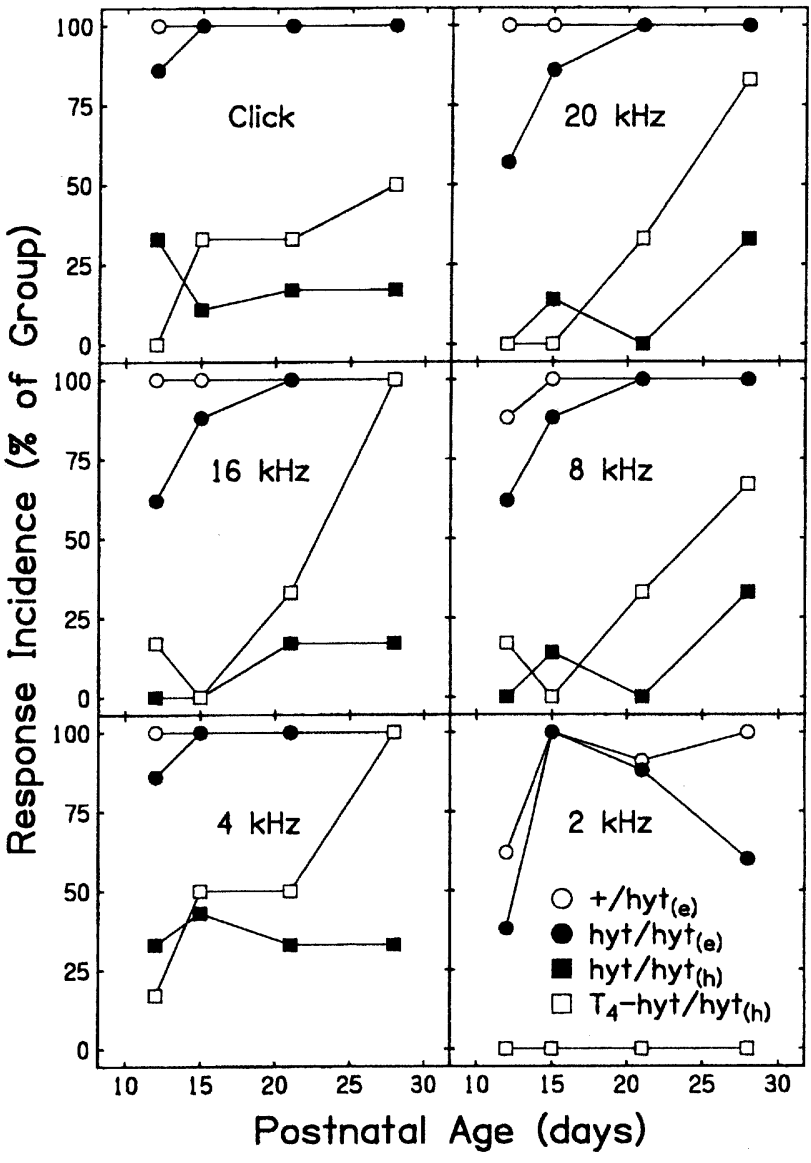

FIG. 5. Developmental changes in response incidence. The percentage of mice responding to clicks and tone bursts is plotted as a function of postnatal age for each study group. The symbol key for all panels is located in the bottom-right panel. Each stimulus was delivered at its maximum output level, which for clicks and 20-, 16, 8-, 4-, and 2-kHz tone bursts corresponded to $122,112,114,118$, 133 , and $112 \mathrm{~dB} S \mathrm{SL}$, respectively. Six to 13 mice were tested in each group at each age.

individual from this group responded to $2 \mathrm{kHz}$.

In an experiment that allowed us to determine whether or not the thyroxin-dependent critical period observed by Deol (1973) in C57BL/Gr mice extended to P10 in Tshr mutants, thyroxin was administered to $h_{y t} /$ hyt $_{(\mathrm{h})}$ animals for the first 10 postnatal days, after which individuals were studied on the standard test dates. Representatives of this group are designated $\mathrm{T}_{4}-h y t / h y t_{(\mathrm{h})}$ in Figure 5 (open squares), and it is clear that $\mathrm{T}_{4}$ treatment was effective for all stimulus conditions except $2 \mathrm{kHz}$. Interestingly, however, recovery was age dependent such that the majority of treated animals responded regardless of stimulus type on P28 (except at $2 \mathrm{kHz}$ ).

Another way of looking at responsiveness from a population perspective is to consider response incidence rates for each experimental group as a function of stimulus level, as shown in Figure 6. This approach 


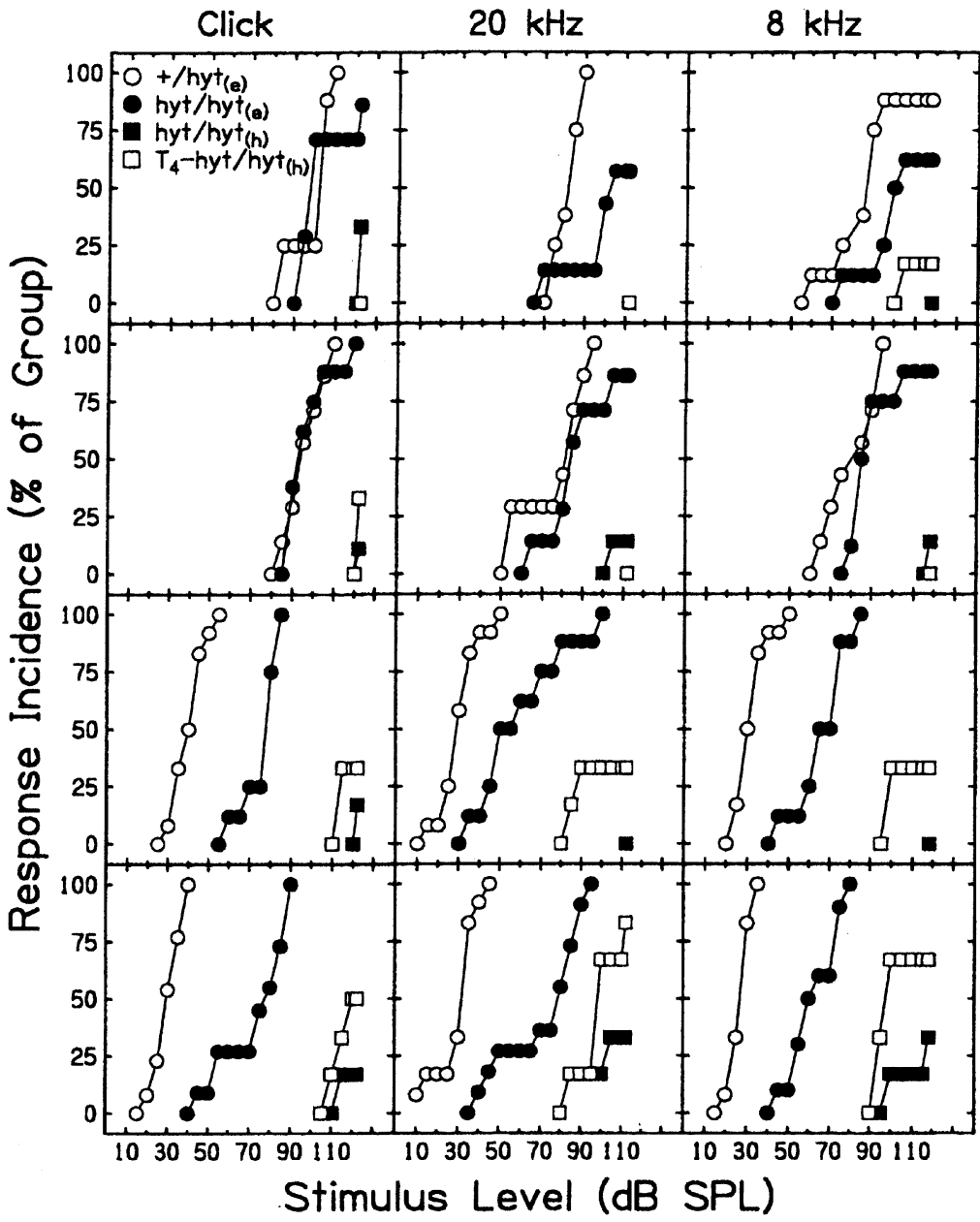

P12

P15

P21

FIG. 6. Response incidence-vs.-stimulus level functions. The percentage of mice within each P28 experimental group responding to clicks, $20 \mathrm{kHz}$, and $8 \mathrm{kHz}$ (columns) is plotted as a function of stimulus level at each of the postnatal ages studied (P12, P15, P21, and P28, top to bottom rows, respectively). The symbol key for all panels is located in the top left panel. Six to 13 mice were tested in each group. allows one to appreciate developmental changes in a group's overall responsiveness by scanning panels in the vertical dimension for each of the stimuli shown (clicks, $20 \mathrm{kHz}$, and $8 \mathrm{kHz}$ ). The severity of the disease among homozygotes born to homozygous dams (filled squares) is apparent in this format in that relatively few members of this group responded to acoustic stimulation, regardless of level or stimulus type, and there was essentially no change in the group's functional status throughout development.

Heterozygotes (open circles), on the other hand, developed normally relative to other mammals, in that three clear stages were identified. First, responsiveness changed very little between P12 and P15. However, significant changes occurred between P15 and P21 and maturity was achieved by P28, if not by P21. Homozygotes born to heterozygous dams (filled circles) also improved with age, with progress occurring along two dimensions: (a) more individuals were responsive at P15 than at P12 at higher levels, and (b) overall group thresholds improved, as depicted by the leftward shift in the curves, although the change was small. The most dramatic intergroup difference was evident between P15 and P21 as heterozygotes acquired adultlike sensitivity and homozygotes that were exposed to thyroxin prenatally stalled developmentally. It is also evident that the consequence of treating homozygotes born to homozygous dams with thyroxin during the first 10 postnatal days was significant in that response incidence increased at high levels, primarily between P21 and P28, although thresholds for this treatment group were essentially unchanged throughout the period of the investigation.

As expected, the percentage of responsive $+/$ hyt $_{(\mathrm{e})}$ animals (open circles) on P28 increased regularly along a steep trajectory with a dynamic range (i.e., the range of levels over which changes in responsiveness of the sample occur) of approximately 20-30 dB, and the most sensitive individuals of the population responded to tone bursts and clicks in the vicinity of 10-15 dB SPL. Homozygous mutants derived from euthyroid dams, the $h y t / h y t_{(\mathrm{e})}$ group, were 25-35 dB less sensitive than heterozygous cohorts, and the dynamic range was 35-45 dB, approximately $15 \mathrm{~dB}$ greater than in heterozygotes. Except for the 2-kHz condition, all individuals in both $+/ h_{y} t_{(\mathrm{e})}$ and hyt/ 


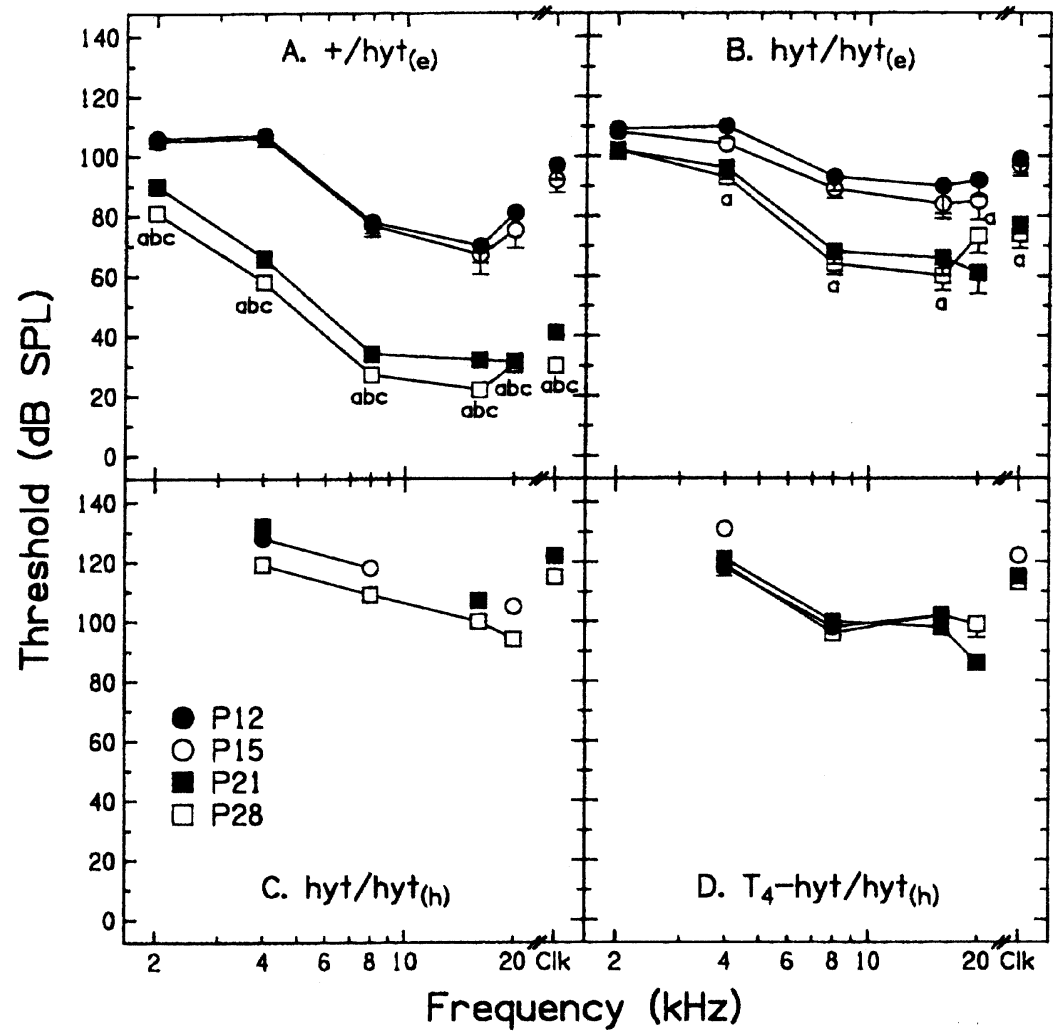

FIG. 7. ABR audiograms for euthyroid and hypothyroid mice. Average ABR thresholds in response to click and tone burst stimuli are plotted for each experimental group (A-D) at each of the ages studied (parameter). Symbol key for all panels indicating postnatal age is shown in C. Error bars represent the SEM. Letter designations next to symbols represent the following statistically significant differences: "a," between P12 and P21 $(p<0.01)$; "b," vs. hyt/hyt ${ }_{(\mathrm{h})}$ and vs. $\mathrm{T}_{4}-$ hyt $_{\text {hyt }}(\mathrm{h})(p<0.01)$ at P15, P21, and P28; "C," $p<0.01$ vs. hyt/hyt $t_{(\mathrm{e})}$ vs. hyt/hyt $t_{(\mathrm{h}),}$ and vs. $\mathrm{T}_{4}-$ hyt/ hyt $_{\text {(h) }}(p<0.01)$ at P28. $h y t_{(\mathrm{e})}$ categories eventually responded to all stimulus types. In stark contrast, homozygotes born to homozygous dams, that is, individuals with absolutely no prior history of $\mathrm{T}_{4}$ exposure, were essentially unresponsive under all conditions. The lowest level that elicited responses in any member of the hyt/hyt $t_{(\mathrm{h})}$ group was in the vicinity of $100 \mathrm{~dB}$ SPL and dynamic ranges were approximately $5-10 \mathrm{~dB}$, although system output limits may have confounded the accurate estimation of this parameter. Even at the highest output levels available, responsiveness was limited to a relatively small portion of the population. Thyroxin treatment during the first 10 postnatal days partially prevented dysfunction in $h_{y} t / h_{t_{(\mathrm{h})}}$ animals, but improvement was meager, with sensitivity enhancement in the range of $5 \mathrm{~dB}$. Dynamic range was also reduced relative to normal animals, possibly a result of system output limitations. In addition, the entire population responded to a highly restricted set of intense stimuli.

\section{ABR thresholds}

Response thresholds were elevated in the $+/$ hyt $_{(\mathrm{e})}$ group through P15 (Fig. 7A), decreased significantly $(p<0.01)$ by $\mathrm{P} 21$, and generally stabilized in the adult range by $\mathrm{P} 28$. An abrupt, albeit small, drop in thresholds was also observed for hyt/hyt (e) animals between P15 and P21 $(p<0.01)$ in response to clicks and tone bursts above $2 \mathrm{kHz}$ (Fig. 7B). In contrast, thresholds remained constantly high during the first 28 postnatal days among placebo and thyroxin-treated homozygotes derived from hypothyroid dams $\left(h_{y} t / h_{\left.t_{(\mathrm{h})}\right)}\right)$ (Figs. 7C and D).

These findings are shown in the form of thresholdvs.-age plots in Figure 8. Homozygotes born to hypothyroid dams $\left(h y t / h t_{(\mathrm{h})}\right)$ (filled squares) were clearly less sensitive to acoustic stimulation than either heterozygotes (open circles) or homozygotes born to euthyroid dams $\left(\right.$ hyt $\left./ h_{y} t_{(\mathrm{e})}\right)$ (filled circles), regardless of age. Thresholds for animals in the $h y t / h_{y} t_{(\mathrm{h})}$ category that responded to acoustic stimulation at all were in the range of $120 \mathrm{~dB}$ SPL and this group remained insensitive to acoustic stimuli throughout the period of the study. For clicks and tone bursts $\geq 4 \mathrm{kHz}$, significant threshold differences on the order of 30-40 dB were evident by P21 when $+/ h y t_{(\mathrm{e})}$ animals were compared with $h y t / h^{\prime} t_{(\mathrm{e})}$ animals. With the exception of the $2-\mathrm{kHz}$ condition, both heterozygotes and homozygotes born to euthyroid dams $\left(h_{y t} / h_{y} t_{(\mathrm{e})}\right)$ acquired sensitivity according to the formula suggested by Walsh et al. (1986a), in which a period of insensitivity is followed by a period of rapid change after which adult values are achieved.

\section{ABR wave latencies}

Following expected developmental trends, absolute response latencies among heterozygotes decreased as a function of age, as shown for responses to clicks, 20 


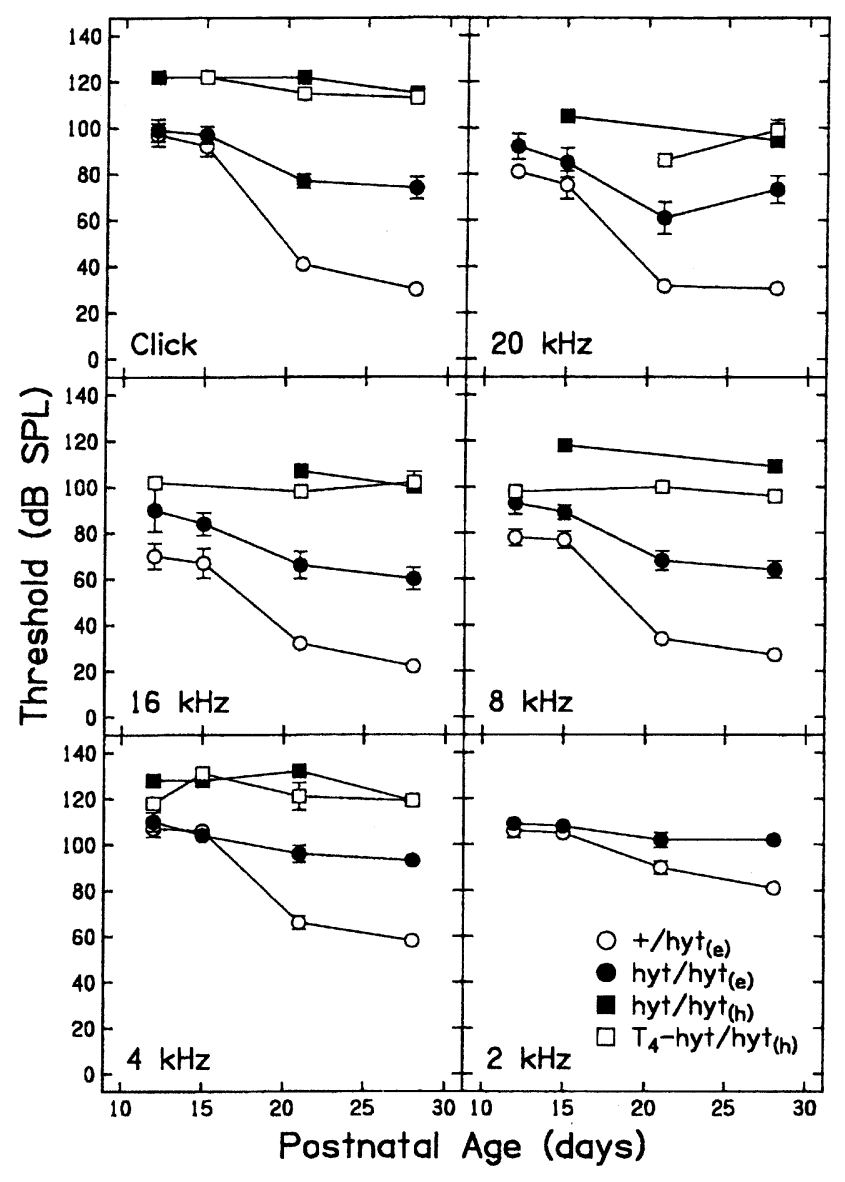

FIG. 8. Maturation of ABR thresholds for euthyroid and hypothyroid mice. Mean ABR thresholds to clicks and tone bursts are plotted as a function of postnatal age for each study group. Symbol key for all panels is shown in the lower-right panel. Error bars represent the SEM.

$\mathrm{kHz}$, and $8 \mathrm{kHz}$ at $90 \mathrm{~dB}$ SPL in Figure 9. Latency decrements followed an essentially exponential time course and either achieved adult values or were within the range of adult values by P21. Similar trends were observed for $h y t / h y t_{(\mathrm{e})}$ animals, with the exception of wave I elicited by clicks and $20-\mathrm{kHz}$ tone bursts. Overall, response latencies in $h y t / h y t_{(\mathrm{e})}$ animals were prolonged relative to those produced by heterozygotes, reflecting, at least in part, the relative insensitivity of hypothyroid animals.

A complete set of latency-intensity curves is shown for individual $+/ h t_{(\mathrm{e})}$ (open symbols) and hyt/hyt $t_{(\mathrm{e})}$ animals (filled symbols) for the $20-\mathrm{kHz}$ condition for the four waves of the ABR in Figure 10. While it is clear that latencies are generally prolonged among $h y t / h_{t_{(\mathrm{e})}}$ individuals relative to $+/ h t_{(\mathrm{e})}$ individuals, group values overlap at most ages, with the notable exception of P21. Latencies of all waves were inversely related to stimulus level for both study groups at all ages. As dynamic range increased with age, slopes of latency-level curves tended to decrease and assumed an exponential form.
Quantitative estimates of latency-level slopes were determined by normalizing each individual's latencies to the value measured at $90 \mathrm{~dB}$ SPL (taking the difference and adding 1), converting to logarithmic values, and performing a least-squares linear regression. The mean slopes of latency-vs.-level curves for all four ABR waves clearly decreased during the first 21 postnatal days in the $+/ h y t_{(\mathrm{e})}$ group and generally appeared to follow a simple exponential time course (Fig. 11). Although there were exceptions (i.e., clicks on P12 and $8 \mathrm{kHz}$ on P15), wave I latency-level slopes were generally shallower than those of later occurring waves until P21 when adultlike values were observed for all conditions. The rate that slopes associated with lateroccurring waves (wave IV in particular) decreased during the first 21 postnatal days had a tendency to be higher than for earlier-occurring waves (waves I and II in particular). This was especially clear for the 20$\mathrm{kHz}$ condition, where, on P12, latency-level curves representing waves III and IV for the $20-\mathrm{kHz}$ condition were steeper than those representing wave II, while slopes representing all three later-occurring waves were similar on P15. This trend was less clear in the case of $8 \mathrm{kHz}$, where the slopes representing wave II latency-level curves were steeper than expected on P12, and in the case of clicks, where similar trends were noted for click responses, although the slopes of waves II and III were indistinguishable from wave I on P12.

Interestingly, the slopes of latency-level curves from $h y t / h_{(} t_{(\mathrm{e})}$ animals were steeper, on average, than those of their heterozygous counterparts after P21, and slope values were generally higher on P28 than on P21 (Fig.11). Because of the small number of responsive animals on P12 and P15, it was not possible to reliably analyze slope trends for those conditions.

The extent to which insensitivity contributed to latency prolongation was estimated by considering latency-vs.-level curves in the context of sensation levels (SL) as shown in Figure 12 for wave I. Based on the similarity of findings derived from SL and SPL analyses, we conclude that threshold differences account for little of the intergroup latency differences observed in this study, i.e., a factor other than threshold difference contributed to latency prolongation in hypothyroid individuals.

\section{ABR interpeak intervals}

In $+/ h y t_{(\mathrm{e})}$ mice, interpeak intervals (IPIs) and central conduction times (CCTs) measured at $90 \mathrm{~dB}$ SPL were prolonged in young animals and decreased during development, reaching adultlike values no later than P21 (Fig. 13). Variability associated with IPIs and CCTs tended to be larger at P12 and P15 than at P21 and P28 because of individual differences in time courses 


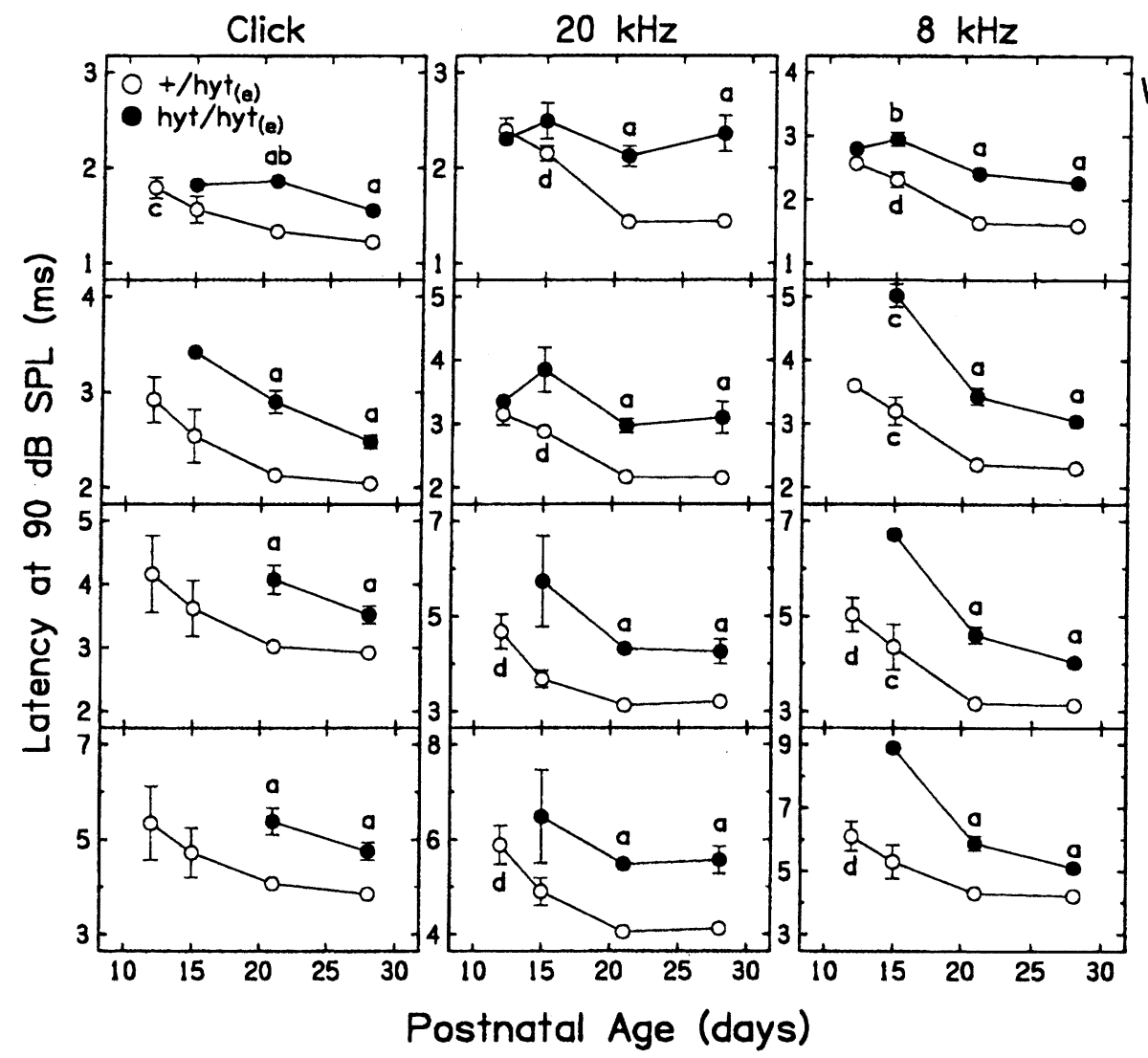

FIG. 9. Development of $A B R$ component latencies. Average latencies of ABR waves I through IV (top to bottom rows) in response to clicks (left column), $20 \mathrm{kHz}$ (center column), and $8 \mathrm{kHz}$ (right column) are plotted as a function of postnatal age for heterozygotes and homozygous mutants born to heterozygous dams. Stimuli were presented at 90 dB SPL. Symbol key for all panels is shown in the upper-left panel. Error bars represent the SEM. Letter designations next to symbols represent the following statistically significant differences between experimental groups: "a," vs. +/hyt $(p<0.001)$ and between ages within a group: "b," vs. P28 $(p<0.01)$; "c," vs. P28 $(p<0.001)$; "d," vs. P21 ( $p$ $<0.001)$.

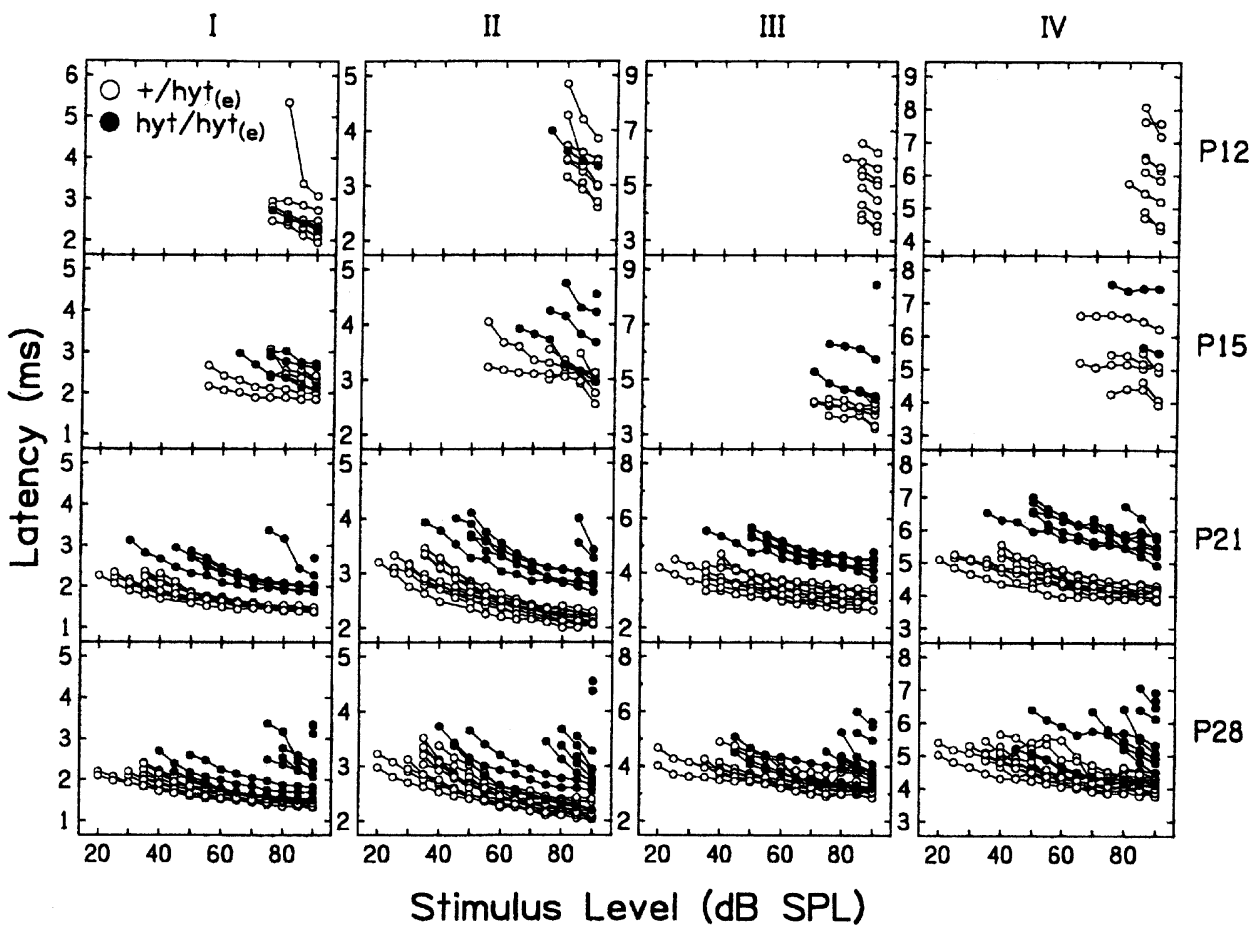

FIG. 10. Latency-level functions for $20 \mathrm{kHz}$. Latency-level functions for ABR waves I through IV (left to right columns) in response to 20 $\mathrm{kHz}$ at the indicated ages (P12, P15, P21, and P28 from top to bottom) for $+/ h t_{(\mathrm{e})}$ and $h y t / h y t_{(\mathrm{e})}$ mice. Symbol key for all panels is shown in the upper-left panel. Each curve represents the responses of an individual animal.

of development. For all stimuli (clicks, $20 \mathrm{kHz}$, and 8 $\mathrm{kHz}$ ), and at almost all ages studied, IPIs associated with $h y t / h y t_{(\mathrm{e})}$ animals were prolonged relative to heterozygotes, indicating that development is delayed in hypothyroid individuals. As in heterozygotes, IPIs decreased with age in homozygous animals, although mean values were typically elevated, even at P28.

Generally, slopes of average IPI-intensity curves 


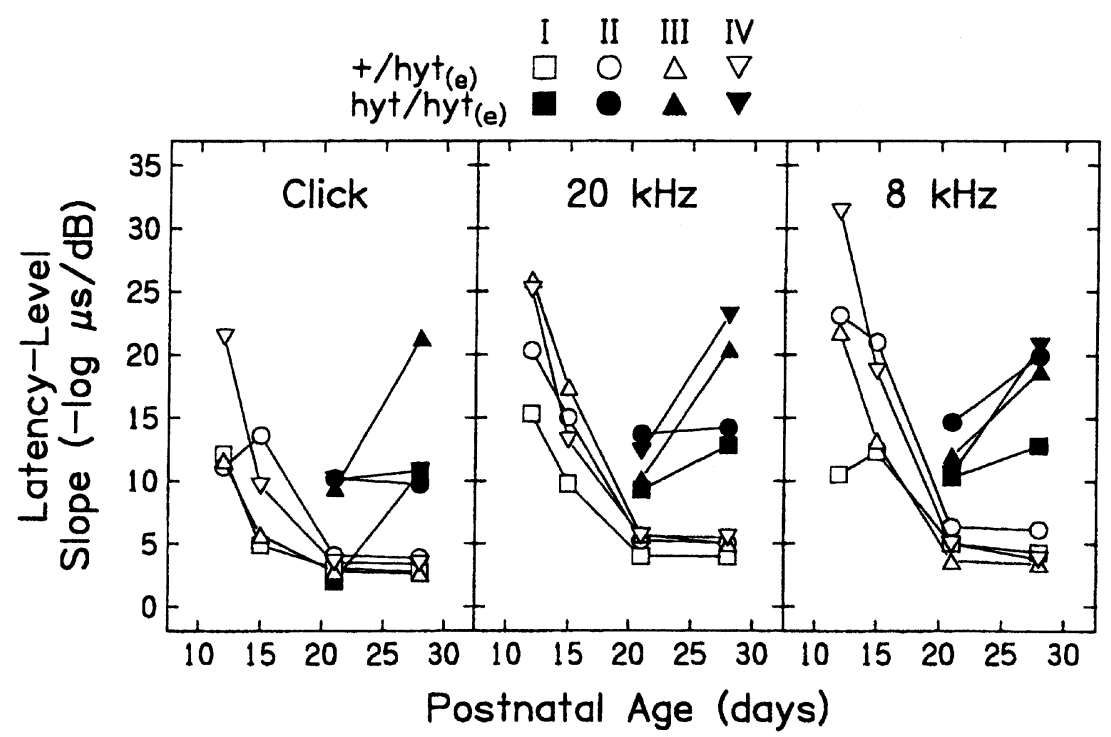

FIG. 11. Developmental changes in slopes of latency-level curves. Mean slopes of latencylevel curves for ABR waves I through IV from +/ $h y t_{(\mathrm{e})}$ (open symbols) and hyt/hyt $t_{(\mathrm{e})}$ (filled symbols) mice in response to clicks (left panel), $20 \mathrm{kHz}$ (middle panel), and $8 \mathrm{kHz}$ (right panel) are plotted as a function of postnatal age. Symbol key for all panels is shown at the top. Slopes were computed by normalizing each subject's latency-level curve to the latency value observed at $90 \mathrm{~dB}$ SPL (taking the difference and adding a value of 1 ), converting the normalized latencies to logarithmic values, and performing a least-squares linear regression. Statistically significant differences were observed between $+/ h t_{(\mathrm{e})}$ and $h y t / h y t_{(\mathrm{e})}$ groups in response to $8 \mathrm{kHz}$ at P21 for waves I and III $(p<0.001)$ and wave II $(p<0.01)$ and at P28 for waves I through IV $(p<0.001)$; in response to $20 \mathrm{kHz}$ at P21 for waves I and II $(p<0.001)$ and waves III and IV $(p<0.01)$ and at P28 for waves I through III $(p<0.001)$ and wave IV $(p<0.01)$; and in response to clicks at P28 for wave III ( $p<0.001$ ).

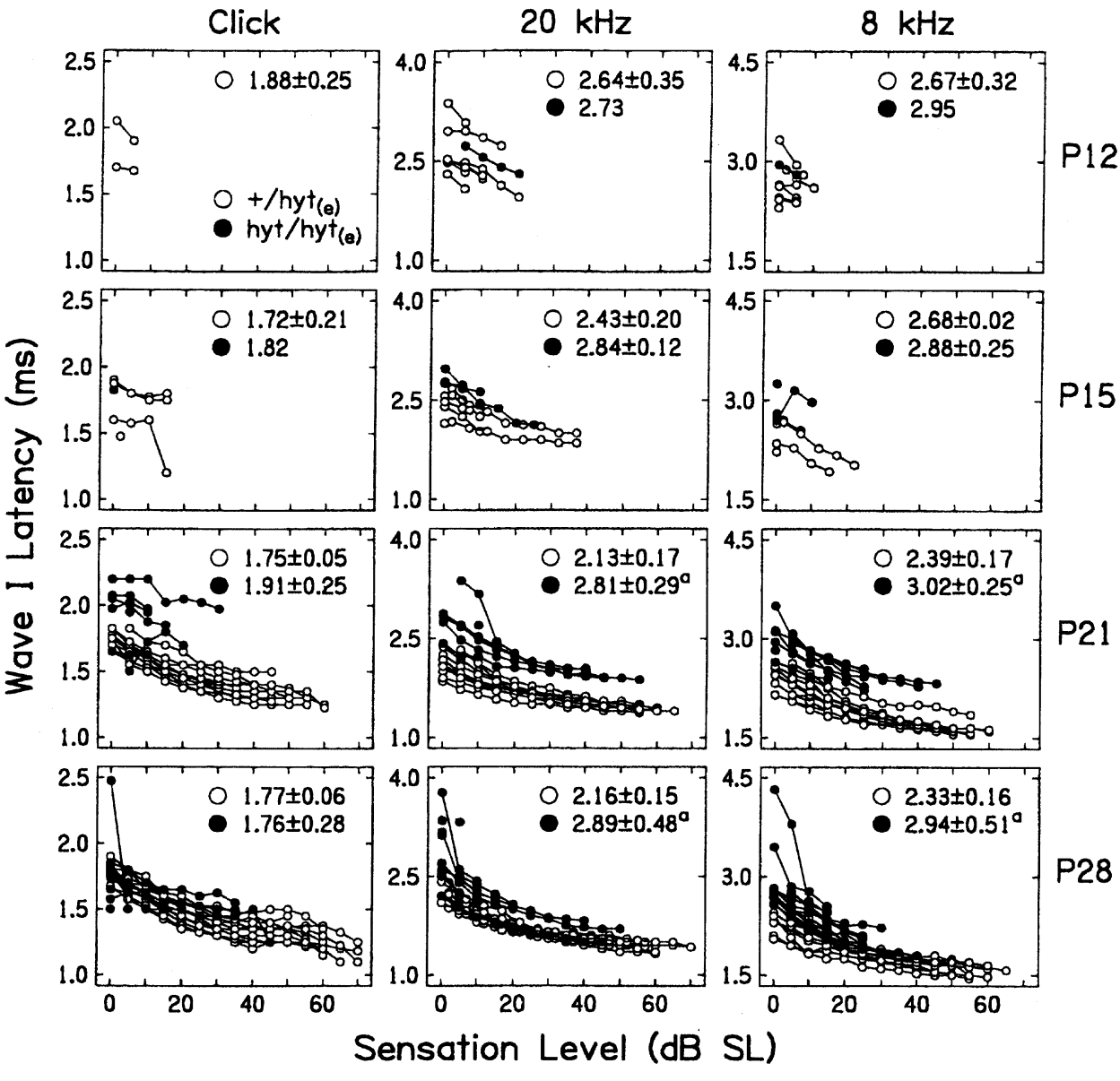

FIG. 12. Latency-sensation level functions. Wave I latencies are plotted as a function of sensation level for clicks (left column), $20 \mathrm{kHz}$ (center column), and $8 \mathrm{kHz}$ (right column) at P12 through P28 (top to bottom rows). Open and filled symbols represent $+/ h t_{(\mathrm{e})}$ and hyt/ $h y t_{(\mathrm{e})}$ groups, respectively. Sensation levels were computed by subtracting the threshold of each individual from the sound pressure level presented. Each curve represents the responses of an individual animal. Latencies (in ms) (mean \pm SEM) measured at threshold $(0 \mathrm{~dB}$ $\mathrm{SL}$ ) are reported for each group. The letter designation "a" indicates a statistically significant difference between the two groups $(p<$ $0.001)$. from young heterozygous animals were steeper than those observed in adults. Level-dependent IPI characteristics were generally mature by P21, as depicted for the 20-kHz condition in Figure 14.
Among $h y t / h y t_{(\mathrm{e})}$ mice studied at P21 and P28, average IPI-vs.-level curves were less regular than their + / $h_{y} t_{(\mathrm{e})}$ counterparts, a finding that is indicative of the high degree of intragroup variability associated with 


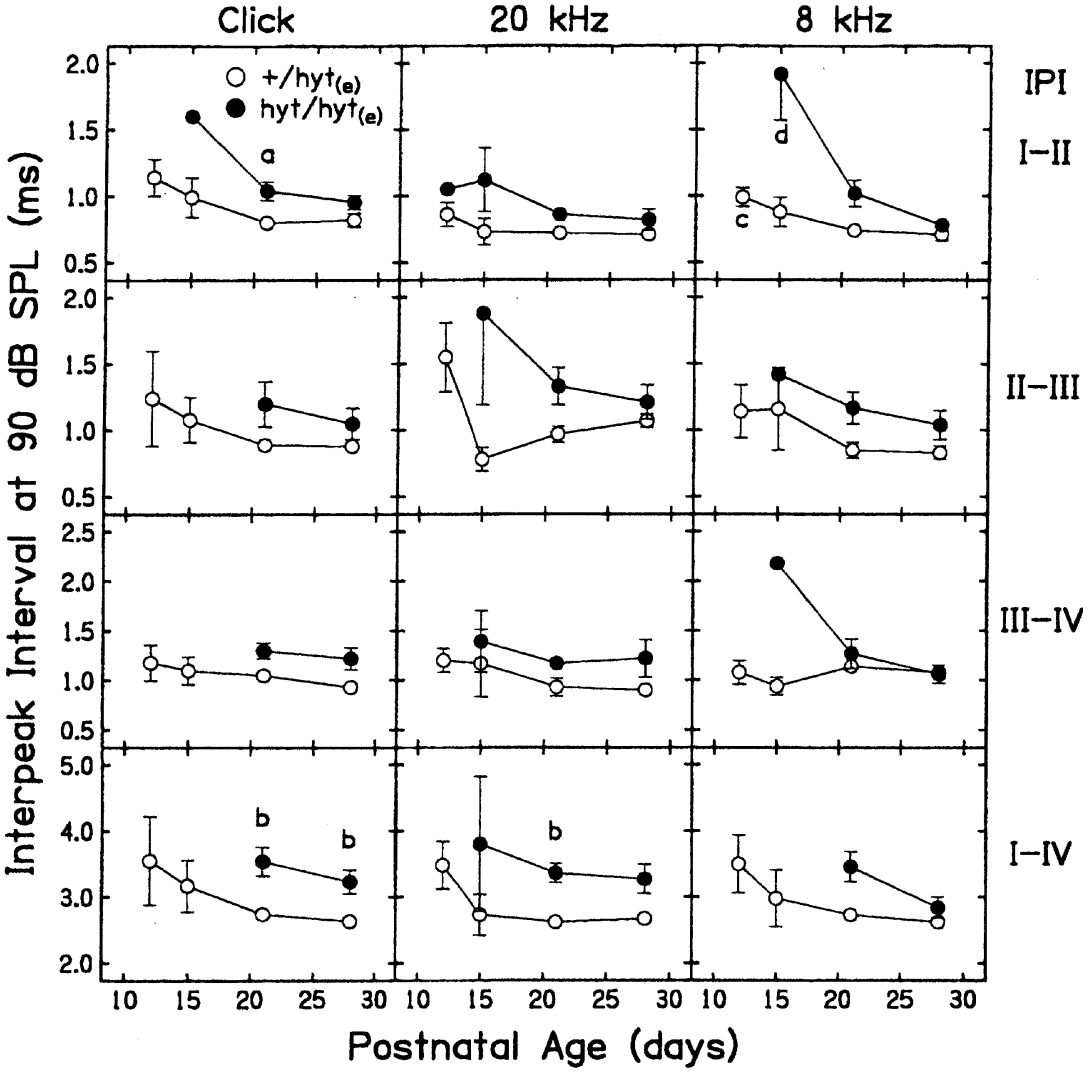

FIG. 13. Maturation of $A B R$ interpeak intervals. Average interpeak intervals (I-II, II-III, III-IV, top 3 rows) and central conduction times (I-IV, bottom row) are plotted in response to clicks (left column), $20 \mathrm{kHz}$ (center column), and $8 \mathrm{kHz}$ (right column) for heterozygotes and homozygous mutants born to heterozygous dams. Stimuli were presented at $90 \mathrm{~dB}$ SPL. Symbol key for all panels is shown in the upper-left panel. Error bars represent the SEM. Letter designations next to symbols represent the following statistically significant differences between experimental groups: "a" vs. $+/$ hyt $t_{\mathrm{e})}(p$ $<0.01)$; "b," vs. $+/ h y t_{(\mathrm{e})}(p<0.005)$ and between ages within a group: "c," vs. P21 $(p<0.01)$; "d," vs. P28 $(p<0.01)$.

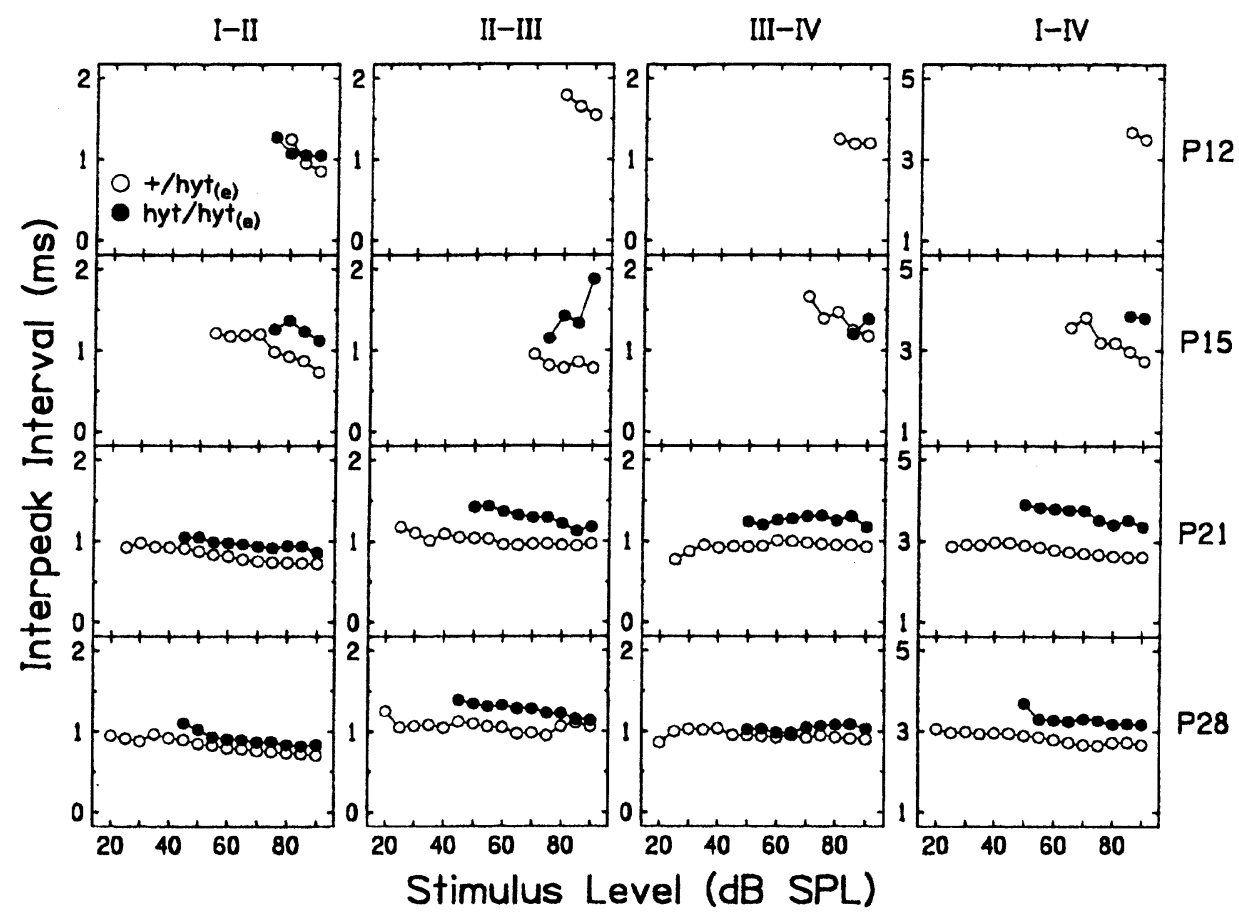

FIG. 14. Interpeak-interval-vs.-stimulus level curves. Average interpeak intervals (I-II, II-III, III-IV) and central conduction times (I-IV) from left to right columns are plotted as a function of stimulus level at P12 through P28 (top to bottom rows) for the $+/$ hyt $_{(\mathrm{e})}$ and hythyt $t_{(\mathrm{e})}$ groups (open and filled symbols, respectively). Responses were obtained using $20-\mathrm{kHz}$ tone bursts. (Symbol key for all panels is shown in the upper-left panel.) Values are included only if two or more individuals from a group were responsive. diseased individuals (Fig. 14, center panels). However, all IPIs representing homozygotes were notably prolonged throughout the dynamic range of response when compared with heterozygotes, although significant differences between the mean slopes of the two groups were not observed. The smallest differences between heterozygotes and homozygotes were observed for the interval between waves I and II, and the largest differences were associated with central conduction time (I-IV interval), suggesting that the 


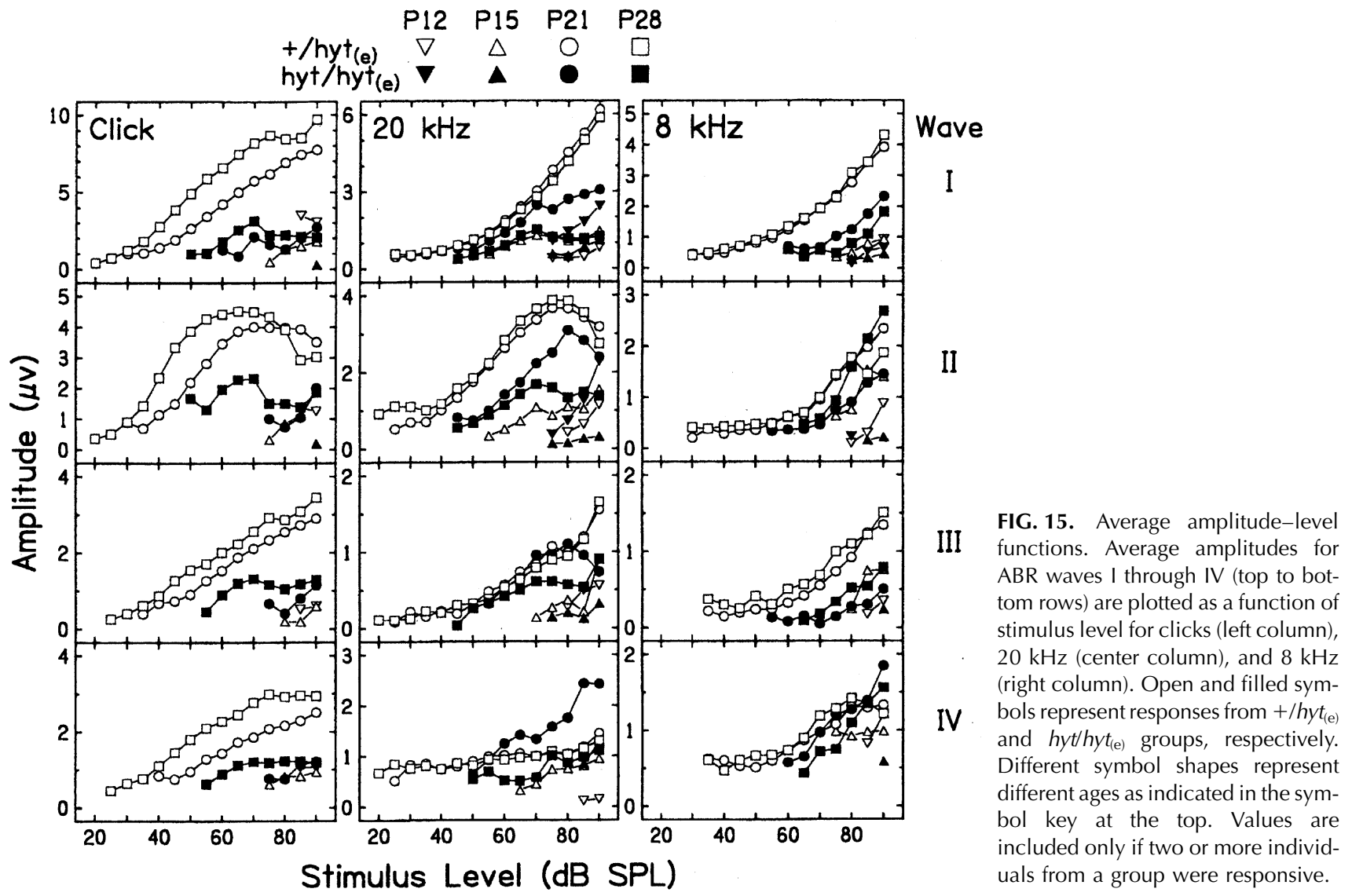

maturation of central conducting paths is delayed longer than are those in the periphery among homozygotes.

\section{ABR wave amplitudes}

As with ABR amplitudes in general, responses were highly variable in all groups studied. However, developmental trends were evident in both heterozygous and homozygous animals. This is most easily seen in a series of average amplitude-vs.-level plots generated from click and tone burst responses for each ABR wave (Fig. 15). Peak amplitudes from both groups were relatively small at P12 and P15 and only high-level stimuli effectively evoked responses from $h y t / h y t_{(\mathrm{e})}$ individuals. In the case of clicks, average amplitudes associated with ABRs from heterozygotes tended to increase between P12 and P21, but most dramatically between P15 and P21. Further growth of amplitudes between P21 and P28 was observed in responses to clicks in heterozygotes, however, for 8 and $20 \mathrm{kHz}$, response amplitudes saturated near P21. In general, the amplitudes of most major waves tended to be smaller in hyt/hyt $t_{(\mathrm{e})}$ animals than those observed in age-matched heterozygous counterparts.

\section{DISCUSSION}

Hearing development is normal in $+/ h y t_{(\mathrm{e})}$ mice

As expected, auditory function in euthyroid $T s h r$ mutant mice develops along a time line much like that of other normal mice, as well as mammals in general. Although the most comprehensive model of auditory system development is based on the cat (Jewett and Romano 1972; Shipley et al. 1980; Walsh et al. 1986a,b,c), the basic plan appears to be conserved among mammals. This view is based on the outcome of similar studies in other strains and species, including gerbil (McFadden et al. 1996), mouse (Henry and Haythorn 1978; Hunter and Willott 1987), rat (Jewett and Romano 1972; Iwasa and Potsic 1982; Rybak et al. 1991; Blatchley et al. 1987), rabbit (Pettigrew and Morey 1987), hamster (Schweitzer 1987), and ferret (Morey and Carlile 1990).

In the majority of mammals thus far studied, auditory function is acquired in three relatively clear stages: (1) a primitive stage characterized by extreme acoustic insensitivity, (2) a dynamic stage that is marked by rapidly improving thresholds, and (3) a refinement stage during which adult function is acquired. As shown in this study, Tshr mutants follow that time 
course precisely. First, 12-day-old $+/ h t_{(\mathrm{e})}$ animals have very high thresholds, relatively flat frequencythreshold curves, and response latencies that are prolonged and amplitudes that are small; second, relatively dramatic developmental changes occur between P15 and P21; and, third, gradual changes occur thereafter, culminating in adultlike conditions by the end of the first postnatal month. Interestingly, at least some strains of mice (i.e., CBA-J) appear to develop relatively early when compared with $T s h r$ heterozygotes and do not pass through the primitive stage referred to above (Mikaelian and Ruben 1965). The comparative significance of that finding is unclear.

Although the anatomy of the Tshr mouse has not been studied developmentally, it is relatively safe to assume that morphological changes in heterozygous hyt mice are similar to changes observed in others, including the CBA/CBA mouse (Lim and Anniko 1985), CBA-J mouse (Mikaelian and Ruben 1965), and the C57BL/6J mouse (Shnerson and Pujol 1983). The final stage of cochlear development occurs rapidly relative to other mammals, such that complete maturity is achieved by the end of the third postnatal week. During this period outer hair cell (OHC) synapses are refined (Kikuchi and Hilding 1965; Lenoir et al. 1980), the tectorial membrane is secreted (Kraus and Aulbach-Kraus 1981; Lim and Anniko 1985), Kolliker's organ is converted to the cuboidal epithelium of adulthood, and supporting cells acquire adultlike stature (Kraus and Aulbach-Kraus 1981). Myelination also occurs during this period and continues well into postnatal life (Webster and Webster 1980). Maturity was essentially achieved in the $+/ h t_{(\mathrm{e})}$ group studied here by $\mathrm{P} 21$, much like that of other rodents who appear mature within two weeks of the onset of hearing (Iwasa and Potsic 1982; Schweitzer 1987).

Perinatal hypothyroidism causes developmental delays and permanent hearing loss in hyt mice

One of the more remarkable findings of this investigation is that, in vivid contrast to heterozygotes, hyt/hyt animals born to hyt/hyt dams remained unresponsive throughout the period of the study, even if treated with thyroxin for the first 10 postnatal days. However, when genotypically identical individuals were born to heterozygous mothers, who were themselves phenotypically normal, partial development occurred (i.e., thresholds improved some, latencies shortened, amplitudes increased, etc.), dramatizing the importance of prenatal thyroxin on the development of auditory function. The anatomical correlates of profound, lifelong hypothyroidism are unknown, although preliminary developmental studies are underway in our laboratory. These early studies suggest that at least certain anatomical features of the end organ of hyt/ hyt animals born to hyt/ hyt dams may be normal from a qualitative perspective, although their development is clearly delayed several days relative to normal littermates. Nonetheless, certain normal-appearing inner-ear features seem to be relatively clear in adult $h y t / h y t$ animals born to euthyroid dams. For example, the tunnel of Corti is open, the inner spiral sulcus is grossly normal in appearance, and upper-tunnel crossing fibers are present that project clearly into the domain of OHCs. These preliminary results suggest that functional deficits may occur in the absence of some obvious anatomical abnormalities, a finding that is reminiscent of Forrest et al.(1996), who observed normal cochlear anatomy in a $\operatorname{TR} \beta$-deficient mouse exhibiting significant inner-ear pathophysiology.

The impact of hypothyroidism on the development of auditory function is also evident in the differences between $+/ h y t_{(\mathrm{e})}$ and $h y t / h y t_{(\mathrm{e})}$ mice reported here. Development was not only delayed in $h y t / h y t_{(\mathrm{e})}$ mice, but response thresholds were grossly elevated on P28 relative to their heterozygous counterparts. Because thresholds measured on P28 were essentially the same as those measured on P21, as well as those in 75-90 day olds (Sprenkle et al. 2001), we conclude that deficits observed here are permanent, as they are in congenitally hypothyroid humans. Similar findings have been reported in propylthiouracil (PTU)-treated rats (Uziel et al. 1981, 1983a,b).

Although the degree of otopathology associated with the $h y t / h y t_{(\mathrm{e})}$ condition has not been studied exhaustively, O’Malley et al. (1995) and Li et al. (1999) have reported extensive abnormalities in adult hyt/ $h y t_{(\mathrm{e})}$ mice at both the light and electron microscopic level. Anomalies described by these authors involve both inner hair cell (IHC) and OHC cytopathology, as well as tectorial membrane (TM) and OHC stereociliary abnormalities, and dysmorphia of the tunnel of Corti, including anomalies of the pillar cell cytoskeleton. Similar irregularities have been observed in hypothyroid rats that include general cytopathology (Uziel et al. 1981, 1983a), metabolic deficits (Uziel et al. 1981), immaturity and agglutination of stereocilia (Uziel et al. 1981), as well as diminished numbers of efferent OHC contacts and postsynaptic specializations (Uziel et al. 1983b). It is notable that OHCs appear to be more sensitive to hypothyroidism than IHCs in both $h y t / h y t_{(\mathrm{e})}$ mice and congenitally hypothyroid rats (Uziel et al. 1983a,b; O’Malley et al. 1995). OHC abnormalities have been detected as early as P3 in PTU-treated rats, well before the expected onset of hearing, and these abnormalities fail to resolve in even fully adult animals, according to Uziel et al. (1985). These findings are consistent with the observation of Uziel et al. (1983b) that OHC differentiation is delayed in hypothyroidism, as is efferent synapse formation on OHCs. 
While extensive otopathology has been reported in $h_{y t} / h_{\text {y }}$ (e) $_{\text {) }}$ and PTU-treated animals (Uziel et al. 1985; O'Malley et al. 1995; Li et al. 1999), reports from other laboratories suggest a somewhat different picture. Deol (1973), for example, found cochleae of mice treated with PTU during the postnatal period, a condition much like that of the hyt/hyt mice born to heterozygous dams studied in O'Malley et al. (1995) and Li et al. (1999) completely normal at the light level of microscopy. Cochlear anatomy is also normal at the light level in mice lacking normal $\beta$ thyroid hormone receptors (Forrest et al. 1996). Neither is there clear evidence of otopathology beyond expected developmental delays in either young or young adult hyt/ hyt mice studied in our laboratory, although we are hesitant to suggest that the TM, for example, is normal in these specimens (Walsh et al. 2000). Although O'Malley and his colleagues point out that certain cochlear anomalies require the electron microscope for detection, other features, like the tunnel of Corti or the gross structure of tunnel pillar cells or the character of the TM, do not, and the resulting picture is confusing. This confusion is not diminished when the degree of pathophysiology is compared with the degree of otopathology reported. It is difficult to understand, for example, how animals exhibiting such extensive pathology could be as responsive as hyt/hyt animals are, particularly in light of the heterogeneous distribution of abnormalities along the cochlear spiral within an individual, e.g., normal-appearing regions were observed adjacent to grossly abnormal regions in O'Malley et al. (1995). The resolution of these questions will be interesting to follow as the anatomical character of affected animals is studied more extensively.

Although the dominant pathology of hyt/hyt animals is clearly sensory in character, CNS abnormalities related to conduction velocity also contribute to the overall pathology of hyt/hyt mice, at least transiently. At least two prospective sources are implicated in this finding: myelination and synapse function. While it is impossible to parse the relative contribution of retarded myelination and synapse abnormality using the methods employed here, myelination delays are known to occur in hypothyroidism (Knipper et al. 1998), as are synapse anomalies (Uziel et al. 1985), suggesting that both elements contribute to delayed response times observed among these animals. Although both IPIs and CCTs were prolonged throughout the study period, they eventually acquire values similar to those observed in heterozygotes (Sprenkle et al. 2001), indicating that the development of central pathways progresses at a remarkably slow pace in hypothyroid individuals. It is likely that other CNS abnormalities will be identified in the future, but their discovery will require the use of more sensitive methods of detection.

Prenatal hypothyroidism profoundly attenuates hearing in the hyt mouse

The profound growth deficits and otopathophysiology observed in hyt mice born to hypothyroid homozygote breeding pairs clearly indicates that maternal thyroid hormones significantly contribute to both somatic and auditory development, at least in hypothyroid individuals. Because of its genetic character, the Tshr mouse can be readily exploited in the effort to understand the importance of maternal hypothyroidism on progeny that are genetically normal and those that are not with respect to thyroid hormone production. In most experimental studies, hypothyroidism is induced starting at the age of autonomous secretion of thyroid hormones (or later) and requiring the treatment of both dams and pups and potentially producing changes in both the dam and fetus. To our knowledge, the most directly useful comparative study is Deol's (1973) report of PTU-induced hypothyroidism in the C57 mouse. By exposing dams and pups to PTUtreated drinking water, Deol (1973) found cochlear defects and impairment of the pinna (startle) response to be severe when PTU treatment was initiated on or prior to the 15th gestational day, consistent with our findings in the $h y t / h t_{(\mathrm{h})}$ mouse. Surprisingly, however, he found no permanent reflex impairment or significant anatomical defects when PTU exposure was delayed until the time of birth or when PTU exposure was accompanied by $\mathrm{T}_{4}$ replacement delivered as late as the time of birth.

There are two reasons that very few experimental models have explored the effects of combined maternal/fetal hypothyroidism on mammalian hearing development. First, there is the practical problem of obtaining viable litters from hypothyroid dams (Hendrich et al. 1976), and, second, and perhaps more importantly, the common view that embryonic development occurs independent of thyroid hormone influences. At the center of this debate is the question of placental transport and metabolism of thyroid hormones that remains a controversial issue complicated by mechanisms that may be species- and/or stage-specific (Fisher 1986; Emerson and Braverman 1991). In the rat, clearly detectable amounts of $\mathrm{T}_{4}$ and to a lesser extent its deiodinated metabolite $\mathrm{T}_{3}$, have been measured in fetal serum prior to the onset of fetal secretion (Calvo et al. 1990). Furthermore, the fetal brain has been shown to concentrate maternal $\mathrm{T}_{4}$ (Morreale de Escobar et al. 1985; Ruiz de Oña et al. 1988). In addition, receptors for $T_{3}$ are present in the neural tube from gestational day 11.5 (Bradley et al. 1992) and in the cochlea from gestational day 12 (Bradley et al. 
1994). In humans, $T_{3}$ receptor occupancy is $25 \%$ at 10 weeks into gestation, well before the onset of autonomous secretion at week 12 (Ferreiro et al. 1988). These findings suggest that thyroid hormones might regulate morphogenesis and associated cytodifferentiation in the rodent ear very early in development.

\section{CONCLUSIONS}

Although acoustic thresholds were in the vicinity of $120 \mathrm{~dB}$ SPL throughout the study period and the group was unresponsive to acoustic stimulation prior to that age, as a general rule, $\sim 25 \%$ of homozygotes born to homozygous dams did respond to intense stimulation in the range of 115-120 dB SPL on P28 and 30\% of the population responded to $4-\mathrm{kHz}$ tone bursts at $133 \mathrm{~dB}$ SPL, regardless of age. These data collectively suggest that hypothyroid animals not exposed to prenatal thyroxin do develop auditory function during the first postnatal month, but improvements are negligible, leaving 28-day-olds profoundly impaired.

Homozygotes born to normal, euthyroid dams were generally less sensitive to acoustic stimulation than heterozygotes, who are acoustically normal, throughout the first month of life, but they showed normal developmental tendencies or stages. As a group, these animals exhibited more moderate auditory deficits, highlighting the crucial role of prenatal (maternal) thyroid hormone on auditory system development.

Homozygotes treated with thyroxin during the first 10 postnatal days of life but born to hypothyroid dams were barely distinguishable from untreated cohorts, although as a population they were far more responsive than untreated individuals, suggesting that thyroxin can restore passive aspects of transduction lost to the disease, but that deficits are permanent under low and moderate levels of stimulation, at least through P28.

Because homozygotes born to homozygous dams are more sensitive at approximately three months of age (unpublished observation) than those studied on P28 here, a more extensive developmental study may reveal a greatly prolonged developmental period among individuals with that background.

\section{ACKNOWLEDGMENTS}

This project was supported by grants from the Deafness Research Foundation and the NIH (DC01007, DC00215, DC00982).

\section{REFERENCES}

Adams PM, Stein SA, Palnitkar M, Anthony A, Gerrity L, ShanKLIN DR. Evaluation and characterization of the hypothyroid hyt/ hyt mouse. I: Somatic and behavioral studies. Neuroendocrinology 49:138-143, 1989.

Albee RR, Mattsson JL, Johnson KA, Kirk HD, Breslin WJ. Neurological consequences of congenital hypothyroidism in Fischer 344 rats. Neurotoxicol. Teratol. 11:171-183, 1989.

ANNIKO M, RosenkVIST U. Tectorial and basal membranes in experimental hypothyroidism. Arch. Otolaryngol. 108:218-220, 1982.

ANTHONY A, Adams PM, STEIN SA. The effects of congenital hypothyroidism using the hyt/hyt mouse on locomotor activity and learned behavior. Horm. Behav. 27:418-433, 1993.

Beamer WG, Cresswell LA. Defective thyroid ontogenesis in fetal hypothyroid (hyt/hyt) mice. Anat. Rec. 202:387-393, 1982.

Beamer WG, Eicher EM, Maltais LJ, Southard JL. Inherited primary hypothyroidism in mice. Science 212:61-63, 1981.

Ben-Tovim R, Zohar Y, Zohiar S, LaUrian N, Laurian L. Auditory brainstem response in experimentally induced hypothyroidism in albino rats. Laryngoscope 95:982-986, 1985.

BlatChley BJ, COOPER WA, COLEMAN JR. Development of auditory brainstem response to tone pip stimuli in the rat. Dev. Brain Res. 32:75-84, 1987.

BRADLEY DJ, TOWLE HC, Young WS III. Spatial and temporal expression of $\alpha$ and $\beta$-thyroid hormone receptor mRNAs, including the $\beta_{2}$-subtype, in the developing mammalian nervous system. J. Neurosci. 12:2288-2302, 1992.

BRadley DJ, Towle HC, Young WS III. $\alpha$ and $\beta$ thyroid hormone receptor (TR) gene expression during auditory neurogenesis: Evidence for TR isoform-specific transcriptional regulation in vivo. Proc. Natl. Acad. Sci. USA 91:439-443, 1994.

Calvo R, Obregón MJ, Ruiz de oña C, escobar del Rey F, MorREALE DE EsCOBAR G. Congenital hypothyroidism, as studied in rats. Crucial role of maternal thyroxine but not of 3,5,3'-triiodothyronine in the protection of the fetal brain. J. Clin. Invest. 86:889-899, 1990.

Comer CP, NorTon S. Effects of perinatal methimazole exposure on a developmental test battery for neurobehavioral toxicity in rats. Toxicol. Appl. Pharmacol. 63:133-141, 1982.

DEOL MS. An experimental approach to the understanding and treatment of hereditary syndromes with congenital deafness and hypothyroidism. J. Med. Genet. 10:235-242, 1973.

Di Lorenzo L, Foggia L, Panza N, Calabrese Mr, Motta G, Tranchino G, Orio JR F, LOMbardi G. Auditory brainstem responses in thyroid diseases before and after therapy. Horm. Res. 43:200-205, 1995.

EMERSON CH, BraVERMAN LE. Transfer and metabolism of thyroidrelated substances in the placenta. Adv. Exp. Med. Biol. 299:181196, 1991.

ERF GF. Immune development in young-adult C.RF-hyt mice is affected by congenital and maternal hypothyroidism. Proc. Soc. Exp. Biol. Med. 204:40-48, 1993.

Ferreiro B, Bernal J, Goodyer CG, Branchard CL. Estimation of nuclear thyroid hormone receptor saturation in human fetal brain and lung during early gestation. J. Clin. Endocrinol. Metab. 67:853-856, 1988.

FISHER DA. The unique endocrine milieu of the fetus. J. Clin. Invest. 78:603-611, 1986.

Forrest D, Erway LC, Ng L, Altschuler R, Curran T. Thyroid hormone receptor beta is essential for development of auditory function. Nat. Genet. 13:354-357, 1996.

Gabrion J, Legrand C, Mercier B, Harricane M-C, Uziel A. Microtubules in the cochlea of the hypothyroid developing rat. Hear. Res. 13:203-214, 1984.

Goldey ES, Kehn LS, Lau C, Rehnberg GL, Crofton KM. Developmental exposure to polychlorinated biphenyls (Aroclor 1254) causes hypothyroidism and hearing deficits in rats. Toxicol. Appl. Pharmacol. 135:77-88, 1995a. 
Goldey ES, KeHn LS, ReHnBerg GL, Crofton KM. Effects of developmental hypothyroidism on auditory and motor function in the rat. Toxicol. Appl. Pharmacol. 135:67-76, 1995b.

HÉBERT R, LANGLOIS J-M, Dussault JH. Effect of graded periods of congenital hypothyroidism on the peripheral auditory evoked activity of rats. Electroencephalogr. Clin. Neurophysiol. 62:381387, 1985a.

Hébert R, Langlois J-M, Dussault JH. Permanent defects in rat peripheral auditory function following perinatal hypothyroidism: Determination of a critical period. Dev. Brain Res. 23:161-170, 1985b.

Hendrich CE, Porterfield SP, Henderson J, Galton VA. A comparison of the effects of altered thyroid and parathyroid function on reproduction in the rat. Horm. Metab. Res. 8:220-226, 1976.

HENRY KR, HAYTHORN MM. Effects of age and stimulus intensity on the far-field auditory brain stem potentials in the laboratory mouse. Dev. Psychobiol. 11:161-168, 1978.

HUNTER KP, WILLOTT JF. Aging and the auditory brainstem response in mice with severe or minimal presbycusis. Hear. Res. 30:207218, 1987.

IWASA H, POTSIC WP. Maturational change of early, middle, and late components of the auditory evoked responses in rats. Otolaryngol. Head Neck Surg. 90:95-102, 1982.

JEWETT DL, RoMANO MN. Neonatal development of auditory system potentials averaged from the scalp of rat and cat. Brain Res. 36:101-115, 1972 .

KikUCHI K, Hilding DA. The development of the organ of Corti in the mouse. Acta Otolaryngol. 60:207-222, 1965.

Knipper M, Bandtlow C, Gestwa L, Kopschall I, Rohbock K, Wiechers B, Zenner HP, Zimmermann U. Thyroid hormone affects Schwann cell and oligodendrocyte gene expression at the glial transition zone of the VIIIth nerve prior to cochlea function. Development 125:3709-3718, 1998.

Kraus H-J, Aulbach-Kraus K. Morphological changes in the cochlea of the mouse after the onset of hearing. Hear. Res. 4:89102, 1981.

Laffan EW, Lisciotto CA, Gapp DA, Weldon DA. Development of rotorod performance in normal and congenitally hypothyroid mutant mice. Behav. Neural Biol. 52:411-416, 1989.

Legrand C, Bréhier A, Clavel MC, Thomasset M, Rabié A. Cholecalcin (28-kDa CaBP) in the rat cochlea. Development in normal and hypothyroid animals. An immunocytochemical study. Dev. Brain Res. 38:121-129, 1988.

Lenoir M, Shnerson A, Pujol R. Cochlear receptor development in the rat with emphasis on synaptogenesis. Anat. Embryol. 160:253-262, 1980 .

Li D, Henley CM, O'Malley BW JR. Distortion product otoacoustic emissions and outer hair cell defects in the hyt/hyt mutant mouse. Hear. Res. 138:65-72, 1999.

LI J, CHOw SY. Subcellular distribution of carbonic anhydrase and $\mathrm{Na}+, \mathrm{K}(+)-$ ATPase in the brain of hyt/hyt hypothyroid mice. Neurochem. Res. 19:83-88, 1994.

Lim DJ, ANNiKo M. Developmental morphology of the mouse inner ear. Acta Otolaryngol. Suppl. 422:1-69, 1985.

McFadden SL, Walsh EJ, McGeE J. Onset and development of auditory brainstem responses in the Mongolian gerbil (Meriones unguiculatus). Hear. Res. 100:68-79, 1996.

MEYERHOFF WL. Hypothyroidism and the ear: Electrophysiological, morphological, and chemical considerations. Laryngoscope 89:125, 1979.

Meza G, Acuña D, Peñaloza Y, Poblano A. Congenital hypothyroidism. Vestibular and auditory damage in the pigmented rat. Ann. N. Y. Acad. Sci. 630:274-276, 1991.

Mikaelian D, Ruben RJ. Development of hearing in the normal CBA-J mouse. Correlation of physiologic observations with behavioral responses and with cochlear anatomy. Acta Otolaryngol. 59:451-461, 1965.
Morey AL, CARLILE S. Auditory brainstem of the ferret: Maturation of the brainstem auditory evoked response. Brain Res. Dev. Brain Res. 52:279-288, 1990.

Morreale de Escobar G, Pastor R, Obregón MJ, Escobar del REY F. Effects of maternal hypothyroidism on the weight and thyroid hormone content of rat embryonic tissues, before and after onset of fetal thyroid function. Endocrinology 117:1890$1900,1985$.

Noguchi T, Sugisaki T. Hypomyelination in the cerebrum of the congenitally hypothyroid mouse (hyt). J. Neurochem. 42:891893, 1984

O'MAlley BW JR, Li D, Turner DS. Hearing loss and cochlear abnormalities in the congenital hypothyroid (hyt/hyt) mouse. Hear. Res. 88:181-189, 1995.

Pettigrew AG, Morey AL. Changes in the brainstem auditory evoked response of the rabbit during the first postnatal month. Brain Res. Dev. Brain Res. 33:267-276, 1987.

Post JT, Hypothyroid deafneŝs. Laryngoscope 74:221-232, 1964.

Prieto JJ, Rueda J, Merchan JA. The effect of hypothyroidism on the development of the glycogen content of organ of Corti's hair cells. Brain Res. Dev. Brain Res. 51:138-141, 1990.

Rabié A, Ferraz C, Clavel M-C, Legrand C. Gelsolin immunoreactivity and development of the tectorial membrane in the cochlea of normal and hypothyroid rats. Cell Tissue Res. 254:241-245, 1988.

Ruiz de Oña C, Obregón MJ, Escobar del Rey F, Morreale de Escobar G. Development changes in rat brain $5^{\prime}$-deiodinase and thyroid hormones during the fetal period: The effects of fetal hypothyroidism and maternal thyroid hormones. Pediatr. Res. 24:588-594, 1988.

Rybak LP, Whitworth C, Scott V, Weberg AD, BhardWai B. Rat as a potential model for hearing loss in biotinidase deficiency. Ann. Otol. Rhinol. Laryngol. 100:294-300, 1991, DOI:10.1007/ s101620010076.

SchWEITZER L. Development of brainstem auditory evoked responses in the hamster. Hear. Res. 25:249-255, 1987.

Shipley C, Buchwald JS, NoRMan R, GUThrie D. Brain stem auditory evoked response development in the kitten. Brain Res. 182:313-326, 1980.

Shnerson A, Pujol R, Development: Anatomy, electrophysiology, and behavior. Willott JF, The Auditory Psychobiology of the Mouse. In: Charles C. Thomas Springfield, IL, 1983, 395-425.

Sprenkle PM, McGee J, Bertoni JM, Walsh EJ. Consequences of hypothyroidism on auditory system function in Tshr mutant (hyt) mice. J. Assoc. Res. Otolaryngol. 2001, DOI:10.1007/ s101620010076.

Stein SA, McIntire DD, KirkPatrick LL, Adams PM, Brady ST. Hypothyroidism selectively reduces the rate and amount of transport for specific SCb proteins in the hyt/hyt mouse optic nerve. J. Neurosci. Res. 30:28-41, 1991.

Stein SA, Oates El, Hall CR, Grumbles RM, Fernandez LM, TAYLOR NA, PUETT D, JIN S, Identification of a point mutation in the thyrotropin receptor of the hyt/hyt hypothyroid mouse. Mol. Endocrinol. 8:129-138, 1994.

Stein SA, Shanklin DR, Krulich L, Roth MG, Chubb CM, Adams PM. Evaluation and characterization of the hyt/hyt hypothyroid mouse. II. Abnormalities of TSH and the thyroid gland. Neuroendocrinology 49:509-519, 1989.

Uziel A, Gabrion J, OHResser M, Legrand C. Effects of hypothyroidism on the structural development of the organ of Corti in the rat. Acta Otolaryngol. 92:469-480, 1981.

Uziel A, Legrand C, Ohresser M, Marot M. Maturational and degenerative processes in the organ of Corti after neonatal hypothyroidism. Hear. Res. 11:203-218, 1983a.

Uziel A, Marot M, Rabié A. Corrective effects of thyroxine on cochlear abnormalities induced by congenital hypothyroidism in the rat. II. Electrophysiological study. Brain Res. 351:123-127, 1985 . 
Uziel A, Pujol R, Legrand C, Legrand J. Cochlear synaptogenesis in the hypothyroid rat. Brain Res. Dev. Brain Res. 7:295-301, $1983 b$.

Uziel A, Rabié A, Marot M. The effect of hypothyroidism on the onset of cochlear potentials in developing rats. Brain Res. 182:172-175, 1980 .

Walsh EJ, Cranfill L, Gouthro M, Gratton MA, McGee J. Distortion product otoacoustic emissions in Tshr mutant mice. Assoc. Res. Otolaryngol. Abstr. 23:191-192, 2000.

WALSh EJ, MCGEE J, JaVEL E. Development of auditory-evoked poten- tials in the cat. I. Onset of response and development of sensitivity. J. Acoust. Soc. Am. 79:712-724, 1986a.

WALSh EJ, MCGee J, JaVEL E. Development of auditory-evoked potentials in the cat. II. Wave latencies. J. Acoust. Soc. Am. 79:725$744,1986 \mathrm{~b}$.

WaLsh E, MCGeE J, JaVEl E. Development of auditory-evoked potentials in the cat. III. Wave amplitudes. J. Acoust. Soc. Am. 79:745$754,1986 \mathrm{c}$.

WEBSTER DB, WeBSTER M. Mouse brainstem auditory nuclei development. Ann. Otol. Rhinol. Laryngol. Suppl. 89:254-256, 1980. 